\title{
Haptics in Robot-Assisted Surgery: Challenges and Benefits
}

\author{
Nima Enayati, Elena De Momi, and Giancarlo Ferrigno
}

\begin{abstract}
Robotic surgery is transforming the current surgical practice, not only by improving the conventional surgical methods but also by introducing innovative robot-enhanced approaches that broaden the capabilities of clinicians. Being mainly of manmachine collaborative type, surgical robots are seen as media that transfer pre- and intra-operative information to the operator and reproduce his/her motion, with appropriate filtering, scaling, or limitation, to physically interact with the patient. The field, however, is far from maturity and, more critically, is still a subject of controversy in medical communities. Limited or absent haptic feedback is reputed to be among reasons that impede further spread of surgical robots. In this paper objectives and challenges of deploying haptic technologies in surgical robotics is discussed and a systematic review is performed on works that have studied the effects of providing haptic information to the users in major branches of robotic surgery. It has been tried to encompass both classical works and the state of the art approaches, aiming at delivering a comprehensive and balanced survey both for researchers starting their work in this field and for the experts.
\end{abstract}

Index Terms - Haptics, Robot-assisted surgery, Surgical robotics, MIS minimally invasive surgery

\section{INTRODUCTION}

$\mathrm{H}$ APTIC technology has shown the potential to restore tangibility to human-computer interaction. Despite substantial technological challenge, the spread of hapticallyactive devices in numerous fields appear to be inevitable. In addition to its mainstream applications, haptic feedback has been employed to transform several specialized tasks by providing an auxiliary sensory channel in addition to the often overly burdened visual and auditory channels. The research efforts on specialized tasks have so far been dominated by surgical robotics and simulation [1], [2].

Almost thirty years have passed since the first attempts of using robots in the operating room [3]. Despite the ongoing controversy [4][5], especially on the overall cost-benefit ratio of current systems [6], [7], more operating rooms are equipped with robots every year under the premise that better outcomes could be achieved. Unlike industrial robots that were developed for tedious, repetitive, cumbersome or dangerous tasks, medical robots aim at linking information to interventional actions in a

${ }^{\mathrm{A}} \mathrm{ll}$ authors are with the Department of Electronics, Information and Bioengineering, Politecnico di Milano, 20133, Milan, Italy (e-mail: nima.enayati@polimi.it) more effective way compared to conventional surgery [8]-[10]. This distinction is rooted in the fact that medical actions are based on such a wide range of information such as patientspecific data and general medical knowledge that can only be performed by human reasoning and judgement. To facilitate reasoning, computer-assisted surgical systems fuse and present information in a more purposeful and accessible manner to the physician [11]. Through robots, this information can directly influence the intervention, and potentially improve the quality of the outcomes [12].

Surgical robotic systems are often classified according to their level of autonomy into two categories. The first group, autonomous systems, execute specific tasks automatically with little intervention of the practitioner. Non-autonomous systems on the other hand, aim to reproduce the surgeon's motion in either a master/slave tele-operated configuration or a hands-on configuration. Except for a few examples such as the Robodoc (Curexo Technology Corporation, CA, USA) [13] in total knee arthroplasty or the Cyber-Knife system (Accuray, CA, USA) [14] in radiosurgery, most of surgical robots belong to the second category. This is mainly due to substantial technical complications involved in executing automatic actions in medical interventions with the demanded reliability due to the criticality of the field. Current stage of autonomous execution of surgical subtasks [15] is encouraging, but far from approvable for clinical implementation and replacing clinicians. Robots of non-autonomous type are not designed to replace the surgeon. Rather, they are intended to augment capabilities of the medical staff and enable operations that would not otherwise be physically possible.

Since these collaborative surgical robots aim at extending human capabilities, they clearly should not impede sensory perception of the operator. This, however, has proven to be a major challenge. Vision and haptic are the principal sensory inputs employed by humans in object manipulation tasks. While visual display technology has reached a fairly advanced stage [16], haptic feedback has remained rather underutilized because of practical challenges such as control loop stability. The lack of haptic feedback in a tele-operated system, forces the surgeon to depend merely on visual cues, such as the deformation of tissue under load, to estimate the forces. The likely outcome of misreading these cues is torn tissue or broken suture [17]. The necessity of communicating interaction forces to the user, has 
led some researchers to try alternate displays such as audio or tactile devices to present haptic information indirectly without compromising stability [18].

The objective in providing force information to the operator is often to enhance the tele-manipulation experience so that the operator feels as if he/she were actually present at the remote site. This is commonly referred to as transparency of haptic interfaces [19]. However, haptic technology aims to go even further than providing a realistic illusion of telepresence, by providing the possibility of interacting with operative information via virtually generated force constraints [20]. An active constraint (also known as virtual fixture) [21] is generated by software and attempts to encourage a user's movement along desired paths or prevent he/she from moving into forbidden regions. These methods allow to exploit the precision of robotic systems while keeping the operator in charge.

Haptic technology has had yet another impact on medical community, which is that of computer simulations for surgical training systems [22], [23]. Similar to flight simulator for pilots, these systems can train surgeons in a virtual operating room and at the same time provide quantitative feedback on the performed procedure. Using this feedback, the operator can refine the required skills until gaining a desired level of proficiency before starting the real practice.

Since human tactile and kinesthetic senses present a unique information channel for motor capabilities, numerous researchers have attempted to utilize them in various types of surgical robotic procedures, and investigate their benefits and drawbacks both on real and simulated systems. Many of these works share the same concepts and methods while some have tried alternative approaches.

The primary purpose of this paper is to give an introductory yet extensive overview of the general topic of haptics in surgical robotics. While technical matters are thoroughly discussed, attention has been paid to introduce psychophysical aspects such as those encountered in performance evaluation, and clinical aspects that are often overlooked in engineering studies. Furthermore, principles of operation, advantages and deficits of most recent works in the field are also reviewed to deliver a state-of-the-art outline. In comparison to previous reviews of haptics in robotics surgery, this paper reviews recent works not included in [24] and [25], provides a structured discussion of challenges and obstacles of haptic technologies in robotic surgery in comparison to [26] and delivers a more detailed and extensive analysis on the topic compared to brief reviews such as [27].

The structure of this paper is as follows. In Section II, a brief terminology definition is provided. A plethora of works in the literature have explained these terms comprehensively. Therefore, here the concepts are briefly described and the readers are referred to related references for further information. In Section III, principal challenges that face the incorporation of haptic technology in surgical applications are discussed. Since stability is a major concern in haptic systems, it has been tried to deliver a concise overview of principal approaches, from the classical methods to more recent ones.
Section IV reviews works that have studied the effects of haptic feedback in various surgical procedures. A brief discussion on haptic feedback in surgical simulation system is provided in section $\mathrm{V}$. Alternative methods to display force information are described in section VI and the concept of active constraints is briefly introduced in section VII. Finally, conclusions are drawn in Section VIII.

\section{TERMINOLOGY}

\section{A. Somatic senses}

Although touch is considered one of the five senses of humans, the perception of touch is induced through several modalities including pressure, vibration, stretch (of skin), and temperature. The term "somatic senses" is often used instead of "touch" to better reflect the variety of mechanisms involved in exploring mechanical properties of an object. These mechanisms are usually divided in two general classes, namely cutaneous (tactile) and kinesthetic [28]. Cutaneous information refers to spatial distribution of pressure in the region of touch, and is sensed by skin mechanoreceptors. Kinesthetic information refers to the limbs' kinetic and force data, detected mainly by sensory receptors in the muscles and tendons. Both constituents are indispensable for efficient conduction of motor activities and physical interaction.

\section{B. Haptic interface types}

Haptic devices are commonly categorized based on the somatic modality that they stimulate. Kinesthetic devices aim at generating force/torque feedback and are usually actuated by electric motors. The force feedback can be large enough to stop user's motion, for example, to simulate a rigid contact. While the focus of these interfaces is on displaying force, the presence of physical contact with the tool or handle inevitably induces some level of cutaneous sensation. In contrast, tactile displays convey contact information to the skin, with negligible effect on kinesthetic sensation. They accomplish the cutaneous stimulation in different ways such as electromagnetically actuated needles, shape memory materials, piezoelectric crystals, pneumatic systems, and heating systems [29]. Due to the large variations of cutaneous receptors in type, frequency response and spatial field, tactile displays are usually designed for specific applications such as display of events, contact texture and shape [1]. Compared to kinesthetic interfaces, the design and manufacturing of realistic tactile displays has proven to be more challenging, which has resulted in a far more widespread use of the kinesthetic interfaces [29]. For a review of common types of haptic interfaces and technologies, we refer the reader to [29]-[35].

\section{Admittance vs Impedance}

In the system equivalence notion, electrical, mechanical and thermal actions are divided into flow and effort variables. For instance, in a mechanical system, flow variable can be position, velocity or acceleration and force is considered the effort variable. The impedance/admittance analogies are the two main mechanical-electrical analogies used for representing mechanical systems in the electrical domain. An impedance is 
defined as the ratio of an effort variable over a flow variable and conversely, an admittance is the ratio of a variable of flow over an effort variable. Using these analogies, an impedance haptic device measures motion and displays force, while an admittance haptic device measures force and displays motion. Impedance displays typically exhibit low intrinsic friction and inertia and are highly back-drivable to minimize dynamic distortion of the user's perception. The well-known Phantom haptic displays [36], the Novint Falcon [37], and the Force Dimension's family of haptic devices [38] fall into this class, along with many others. Admittance haptic devices, are generally high-inertia, non-back-drivable mechanisms, equipped with force sensors and driven by a position or velocity control loop. They are often used in applications that require high forces and larger workspaces. The haptic Master [39] is an example of this group of kinesthetic interfaces. Commercially available haptic devices are mostly of the impedance type because of their simpler design and lower production cost.

\section{Surgical robots: Teleoperated vs Hands-on}

Surgical telemanipulators allow the user to perform surgical tasks by a slave robot in a remote environment through commanding a master robot. If the interaction forces of the slave robot are reflected at the master side, the teleoperator is said to be bilaterally controlled. The Raven II is an example of surgical teleoperation systems that encompassing a seven DoF manipulator designed for research in minimally invasive surgery [40]. In hands-on surgical robotic systems, on the other hand, the surgeon and the robot cooperatively move the surgical instrument. This can be considered as a special case of teleoperation, in which the master is located directly on the slave manipulator. The Acrobot (now commercialized as RIO System by MAKO surgical corp., US) is an example of handson robots that is used for total knee replacement [41]. Many reviews on medical and surgical robotics can be found in the literature. The reader is referred to [42], [43] for reviews on medical robotics, [44] for a tutorial on surgical robotics and [45]-[48] for more recent reviews on surgical robotics.

\section{Challenges}

Bi-directionality is the most salient feature of haptic perception. None of the other human sensing modalities involve such a significant interchange of energy between the sensory organ and the environment. Visible light and sound waves are perceived by the corresponding sensory organs in a passive fashion. Unlike these unidirectional perceptions, haptic perception always involves the exchange of mechanical energy. The bi-directionality property is the root of many challenges that not only make the design, production, and implementation of haptic interfaces demanding, but also cause their performance evaluation non-trivial. Further limitations are imposed on haptic systems used in surgical application from strict requirements of surgical tasks, particularly in Minimally Invasive Surgery (MIS), where specific problems are encountered in force/torque measurements. This paper does not aim to delve into any of these technical challenges, as they have been addressed in numerous publications focusing on specific issues. Nonetheless, the authors believe that having a general understanding of technical issues related to implementation and evaluation of haptic technology is crucial for investigating various applications and their roles in surgical robotics and above all, to recognize the obstacles that have precluded this technology from reaching its potential in operating rooms.

\section{A. Stability}

From a control theory perspective, dynamic force interactions can severely affect stability of a closed loop. In the early days of robot force control it was observed that a forcefeedback-controlled robot capable of executing unconstraint motion stably, is likely to show a chattering instability when in contact with rigid surfaces [49]. A bilateral tele-operation system faces further stability challenges because it involves three distinct systems - the human operator, the robot and the environment - that dynamically interact. The overall feedback loop, therefore, includes the human decision and neuromuscular delays, and more importantly, the biomechanical impedance of the user's interaction with the device that can vary to a great degree. In fact, user's grasp may stabilize an otherwise unstable system by dissipating mechanical energy, or conversely, it may destabilize an otherwise stable system by redirecting the energy into the system. Moreover, the presence of communication delays can cause - or aggravate instability. From early 60s the concept of supervisory control was the main approach to cope with the delay [50], [51]. Starting from the mid-1980s, advanced control theory methods such as Lyapunov based analysis gained more attention, and through the implementation of network-based techniques in late 1980s, passivity gained popularity for stabilizing bilateral teleoperation with time delay [52], [53]. Due to the various nonlinearities and the dynamic properties of a human operator, it is difficult to analyze haptic systems in terms of models with known parameters and linear control theory. Instead, passivity which is concerned primarily with the flow of energy between interconnected systems, can be used as a design constraint in controlling these dynamical systems. A system is passive if and only if it cannot produce energy [54]. It is important to note that passivity is by no means an established requirement of dynamical systems. Nevertheless, ensuring passivity in potentially destabilizing interactions suffices to achieve a stable overall system behavior. It can be generally assumed that the environment is passive. It has been shown that, in the frequency range of interest for haptics, the behavior of the human operator can be assumed as a passive environment of arbitrary complexity [55]. Therefore, establishing the passivity of the interfaces between the human and the environment, leads to a closed-loop system compound of passive elements.

In the case of virtual systems, the robot and the environment are replaced by computer simulations. Nevertheless, the dynamic force interaction between the user and the haptic interface imposes similar challenges in maintaining stability. Virtual systems approximate the laws that govern physical systems. The non-idealities introduced by the approximations can severely alter the fidelity of virtual interactions to physical world. Take the collision of two wooden rod as an example. It 
is hard to imagine the rods displaying persistent oscillation after the collision in physical world. In computer haptic interactions however, this is a notorious stability issue, referred to as a limit cycle. Early works on haptics [56] showed that simulating stiff virtual objects, that is a basic yet essential constituent of haptic interaction, is particularly demanding when impedance type devices are used. Factors that can contribute to the injection of energy into the system, or "energy leaks" as was called by Gillespie and Cutkosky [57], such as sampling rate, quantization of measurements, computational delays and amplification, impose strict limitations on stability of haptic control systems [58], [59]. Benefiting from the shared properties of these problems with those of bilateral teleoperation, similar energy-based approaches have been employed to stabilize virtual haptic interactions. In mid 90s, Colgate et al. [60] derived a valuable design guideline as an upper bound for the stiffness of a "virtual wall" composed of a virtual spring and damper, together with a unilateral constraint:

$$
b>\frac{K T}{2}+|B|
$$

where $K>0$ and $B$ are virtual stiffness and virtual damping coefficients, respectively, $T$ represents the sampling period of the simulation and $b$ is the damping of the haptic device. They concluded that to implement stiff and dissipative walls, one has to maximize $b$ and minimize $T$. High sampling rate is a conventional objective, but maximizing damping is clearly against the objective of transparency. At any rate, if the haptic device's intrinsic damping is not adequate to dissipate the energy injected by the non-idealities, the system may become unstable. More than a decade later, Abbot and Okamura [59] extended the condition to explicitly consider sensor quantization:

$$
K \leq \min \left(\frac{2 b}{T}, \frac{2 f_{c}}{\Delta}\right)
$$

where $\Delta$ is the resolution of the optical encoder and $f_{c}$ is the internal Coulomb friction force of the device. Similar to Eq. 1, this condition suggests that to achieve passivity some physical energy dissipation is essential and that the performance of the measurement directly affects maximum achievable stiffness.

In order to decouple the virtual scene generation from the haptic device control problem, a two-port interface between the haptic displays and the virtual environment was introduced by Colgate et al. [61] and Zilles and Salisbury [62]. This "virtual coupling" is a virtual combination of springs and dampers placed between the virtual environment and the haptic device to ensure stability by limiting the impedance presented by the virtual environment. In other words, the virtual coupling provides some further dissipation to prevent active behavior. Adams and Hannaford [63] extended the virtual coupling analysis to a more general framework so that admittance devices could be included. These works derive optimal parameters of the virtual coupling elements that guarantee passivity under all operating conditions. However, the optimal parameters can be too conservative at some interactions and therefore affect user's experience. Rather than using passivity only as a design criteria, Hannaford and Ryu [64], postulated a "passivity observer/passivity controller" to be used in place of fixed-parameter virtual couplings. This controller (and those developed later [65], [66]) explicitly keeps track of the generated energy, and actively dissipates the excess energy to achieve passivity. Thus, it only degrades performance when stability is at risk, and only in the amount needed. A similar approach was taken by Stramigioli et al. [67] to track and dissipate energy excess, however by using a port-Hamiltonian definition.

While works on stability have provided tools that can be used to achieve a stable interaction through haptic interfaces, most of these approaches do so by deteriorating transparency significantly. A controller that is tuned to remain passive with soft tissue interaction may become unstable when in contact with bone. Conversely, a controller that guarantees stability in rigid contacts may exhibit a poor transparency (low sensitivity) in soft tissue interaction. One way to mitigate this trade-off is to exploit the knowledge of the dynamics of the operator inputs and the remote environment (i.e. region of interest on patient's body). Controllers such as those proposed by Haddadi et al. [68] and Willaert et al. [69], use the available information and make assumptions on characteristics of the surgeon and patient to achieve bounded passivity and improve performance without compromising stability. For further readings regarding stability refer to [70]-[72].

Research is still ongoing to enhance the stability and performance of haptic systems. Nevertheless, as far as such performance tradeoffs or counterintuitive behaviors are part of haptically enabled surgical systems, it is helpful for users to become familiar with the ideas used in the design of these systems, mainly to acquire a realistic insight on the performance that can be expected. In addition, since the passivity constraints can still be violated in certain situations by the surgeon, the environment, or the communications network - it is crucial for the software to be able to detect such cases and respond appropriately. Prospective research is expected to yield more robust yet less conservative control methods. On the other hand, improved hardware with higher performances (e.g. in terms of sampling frequencies) will further boost the boundaries of stable interactions through haptic systems.

\section{B. Force and tactile sensing}

Another major challenge for implementation of haptics in surgery is the acquisition of haptic information. Satisfying operating room requirements that put strict limits on size and robustness, and complications arisen by sterilization remain major hurdles in incorporation of sensors in surgical instruments. Furthermore, the sensors must conform to surgical device regulations such as those imposed by the European Medicines Agency (EMA) or the American Food and Drug Administration (FDA) and, needless to say, ought to have a reasonable cost.

The type of complications faced in sensor design, varies depending on various parameters such as the desired number of measured DOFs and the placement of the sensing element [73]. While a full 6 DOF force and torque sensing is the most desirable, fewer DOFs may suffice in many applications. In 
MIS procedures, the instrument is inserted in patient's body through a small incision in which a trocar is placed. It is convenient to place the sensor at the external section of the instrument, but measurements of such a setup will comprise forces from the abdominal wall, shaft contact with nearby tissues, friction, backlash, and instrument's weight and inertia. For a better measurement accuracy, the sensor should be placed close to the interaction region, i.e. the instrument tip. However, the placement of the sensor at the tip enforces design limitations such as robust insulation and size constraint since the sensing device is used inside the body and must pass through the insertion port.

Another critical issue in the design of sensing instruments, especially those that will be inserted inside the human body, is sterilization. The most common method of sterilization is applying saturated steam on the instruments for a duration of about 15 minutes [74]. Therefore, the sensors must be robust to heat, pressure and humidity. Another solution is to employ chemical agents for sterilization which increases the duration of sterilization. Equipment which cannot be sterilized by any of the sterilization methods cannot be reused and need to be economically disposed of.

\section{1) Force measurement systems}

Force sensors are typically single-point sensing mechanisms that can be employed in establishing kinesthetic feedback. Several measurement techniques have been used in surgical force sensing systems, including capacitive, piezoresistive, piezoelectric, and optical-based sensors. The latter sensors do not use electricity in the sensing element and have a more convenient sterilizability that are both valuable advantages in risk management procedures required for medical devices of surgical grade. In addition, optical-based sensors are among the very few suitable choices for Magnetic Resonance Imaging (MRI) guided robots, due to their lack of electrical current. However, limited flexibility of some optical fibers and sensitivity to changes in light intensity caused by tilting of the optical cables or misalignment limits their use. Trejos et al. [74] summarized the MIS force sensing methods available in the literature until July 2009. Recent works on miniature force sensor for Robot-assisted Minimally Invasive Surgery (RMIS) applications have proposed innovative designs to achieve structural simplicity and potential cost effectiveness. Watanabe et al. [75] proposed a single-degree force visualization-system that achieves good resolution and sensitivity, while being low cost and serializable. Hong and Jo [76] fabricated a compliant forceps using two flexure hinges with the capability to measure single-axis pulling and grasping forces at the tip of MIS instrument. It is however generally desirable to have measurements with more degrees of freedom. Uikyum et al. [77] developed a force sensor integrated surgical forceps that measures three-axis pulling forces and a single-axis grasping force thanks to four capacitive transducers. The sensing system was experimentally validated on the Raven-II platform by using a reference force sensor. In [78] the design of a 6-DOF fiberoptic force-torque sensor for minimally invasive robotic surgery is described. The sensor has a diameter of $6.4 \mathrm{~mm}$ and ensures biocompatibility and sterilizability.

\section{2) Tactile measurement systems}

Tactile sensors measure one or more of properties such as pressure, vibration, stiffness, texture, shape, shear and normal forces through physical contact. Many tactile sensing systems are based on the same techniques used in force sensing, differentiated by disparate customization and implementation. The interested reader is directed to a thorough review providing a general overview of tactile technologies [79]. To measure distributed tactile information, rather than measuring a single force, an array of sensing elements is required. Under the restrictions of surgical applications discussed earlier, a multiple-sensing point design can contribute to complications such as problematic integration into surgical instruments and high production cost. In 2012, Tiwana et al. [80] reviewed the state-of-the-art in tactile sensing for biomedical applications including RMIS. The authors of [80] discuss the reasons that have led to "delayed acceptance" of tactile technology, among which cost is mentioned as one of the primary factors. The research is still on-going to provide cost-effective solutions for tactile sensors that satisfy surgical requirements. Examples include: [81] where an optical-based tactile sensor design is proposed that does not require the use of an array of sensors, and [82] where a piezoresistive tactile sensor measures indentation time in addition to force and displacement and is claimed to be cost-effectively batch-producible in miniaturized scale.

In general, it can be said that at the present state of the literature, challenges of haptic measurement in surgical applications are well discussed and understood, and transduction techniques are well established. Recent approaches and customizations draw a promising future for small-sized force and tactile sensors in terms of ease of integration, cost, sterilizability and biocompatibility.

\section{Performance metrics}

To quantify possible benefits of haptic systems in surgical operations, a clear definition of measurable objectives is required. Particular traits of somatic senses make the evaluation of haptic systems often implicit and non-trivial. Vagueness of some performance objectives of surgical tasks only exacerbates the situation. The evaluation of haptic systems is traditionally tied to the concept of tele-presence. As described for teleoperation systems, tele-presence is the sensation of being at the slave site rather than at the master's station. As applied to a virtual environment, tele-presence refers to experiencing the simulated environment rather than the actual physical world [83]. In spite of being an easy notion to understand, numerosity of factors influencing the sense of presence makes the concept ambiguous for quantitative evaluation. The notion of transparency, as in how transparent the intermediate interfaces are to the user, is instead a more suitable criterion. Naturally, control artifacts such as vibrations or hardware interface related distractions like hot grips (due to embedded active actuators) can deteriorate transparency. Assuming a stable control and minimized hardware distractions, transparency of haptic interfaces can be described as how close the user's perceived impedance comes to the remote/virtual environment 
impedance. Ideally, contact with a hard surface such as a bone in the remote environment must feel the same in the master site, and when the slave is in no contact with the remote environment, the master device must reflect no forces.

While transparency is an important index and a good guideline in design and control of haptic systems, it cannot be used as the only metric in some surgical robotic applications. Take for example a virtual constraint that superimposes forces on top of interaction forces in a teleoperation robotic system to encourage the operator to follow a path. In presence of these guiding forces (that would have not been felt, had the user been interacting with the remote environment directly), the system is obviously not trying to achieve transparency, but to improve some form of performance of the task for which the system is used. It is therefore required to define metrics that objectively measure the effectiveness of haptic systems for each specific task. As it will be seen in the next section, for some tasks, this can be done easily. Comparing the number of occurrence of suture breakage or tissue tearing in a set of robot-assisted operations with and without haptic feedback is an example. For some other tasks, especially those in which accuracy is important, the definition of clear objectives can be more challenging. Accuracy of outcomes is not an easy measure to demonstrate, particularly for soft tissue surgery. Even in cases such as rigid bone machining in orthopedic surgery, the required accuracy is difficult to quantify and there is often disagreement on what forms a misalignment that will cause failure or will result in patient pain [84]. Other objective factors such pre- and intra-operative time and costs of operation are to be taken into account as well. Decreasing the time of operation particularly in cases where implementing robotic systems have been reported to elongate the operative time [85], is an important objective.

Another important consideration in objective evaluation of haptic systems for surgical robotic applications is the level of expertise of the subjects who participate in experiments. Studies such as [86] have demonstrated that expert surgeons could obtain significantly higher scores in experiments, than those of the non-experts. It is common to perform experimentation using participants with little/no surgical experience. Although this is an acceptable preliminary evaluation, methods must ultimately be evaluated in experiments with surgeons, expecting that there may be considerable differences in the outcomes; a device that is proven to have outstanding results in tests with non-experts may show little improvements when used by surgeons, due to, for instance, their superior hand-eye coordination and motor skills.

On the other hand, there is the distinct necessity of performing subjective evaluation of the outcomes. In objective evaluation, the performance of successfully completed defined tasks through a haptically enabled system is graded. Subjective evaluation focuses on the operator's feelings and perception and is often performed by questionnaires asking the operator about her/his personal opinion and feelings [87]. Subjective study can point out issues that may not be uncovered in objective evaluation. For instance, a haptically-enabled assistance system may exhibit statistically significant accuracy enhancement in objective evaluation of a surgical task. However, surgeons may exhibit reluctance to implement the system if, for example, it increases greatly the amount of preoperative work.

\section{HAPTICS IN SURGICAL TASKS}

In the context of surgical robotics, many works have studied the impacts of haptic feedback in terms of safety, accuracy, time and costs in various robot-assisted tasks. In this section, some of these studies are reviewed and their results are discussed. Safety enhancement is suggested in many of these works. Especially those that involve force-critical tasks such as suturing or soft tissue manipulation. Regarding accuracy, haptic feedback is shown to be important in performing surgical tasks with complex kinematics and it can ameliorate precision and enhance motor-skill learning [88], [89] when using instruments with limited maneuverability, as is the case in MIS. As for improvements in speed and time saving, lack of haptic feedback can force the surgeon to slow down their maneuvers to investigate visual cues for example, and thus prolonging the operation time. As indirect outcomes, the mentioned enhancements can lead to improvements in aesthetic aspects, patient pain and recovery time.

Table I lists the surgical robotic systems that possess haptic capabilities. There is still no RMIS system available in the market that provides haptic feedback (as of November 2015). The only commercially available surgical robotic systems are RIO system [90] and ROSA [91], that provide force feedback in the form of active constraints in hands-on mode to limit user's motion.

\section{A. General Minimally invasive surgery}

Minimally invasive surgery, also known as laparoscopic or keyhole surgery, is an operation of performing surgery through small incisions with specially designed slender instruments and endoscopic cameras. Compared to open surgery, MIS aims to minimize invasiveness which results in distinct advantages such as reduction of tissue trauma, intraoperative blood loss, postoperative infection risk, patient pain, aesthetic aspects and recovery time. Nevertheless, there are some drawbacks, namely counter-intuitive motion of the instrument (that pivots around the incision point), deteriorated vision, and depriving the surgeon of direct haptic sensation [92]. In some cases such as colorectal surgery, MIS has been associated with an even higher intraoperative complication rate than open surgery [93]. These drawbacks motivated the introduction of RMIS with promising advantages such as helping the surgeon regain dexterity, optimal hand-eye alignment, motion scaling and tremor filtering. While there is no consensus on benefits of RMIS for all surgical procedures, many studies report positive results. To conform with the previous example of colorectal surgery, we refer to a meta-analysis work [94] including16 studies comparing RMIS and MIS in patients with colorectal diseases which concludes that robotic colorectal surgery is a "promising tool".

The $d a$ Vinci surgical system (Intuitive Surgical, US) is the 
TABLE I

LIST OF SURGICAL ROBOTIC SYSTEMS WITH HAPTIC FEEDBACK CAPABILITIES

\begin{tabular}{llll}
\hline \hline Name & Producer & Availability & Procedures \\
\hline RIO System [90] & MAKO Surgical Corp., US & Commercially available & Orthopaedic Surgery (Hands-on) \\
\hline ALF-X [178] & TransEnterix, US & $\begin{array}{l}\text { Upcoming for commercial } \\
\text { exploitation }\end{array}$ & RMIS \\
\hline $\begin{array}{l}\text { SPORT (Formerly Amadeus) } \\
\text { [179] }\end{array}$ & Titan Medical Inc., Canada & $\begin{array}{l}\text { Upcoming for commercial } \\
\text { exploitation }\end{array}$ & Single-site RMIS \\
\hline ACTIVE [180] & $\begin{array}{l}\text { European FP7 consortium, led by } \\
\text { Politecnico di Milano, Italy }\end{array}$ & Research prototype & Neurosurgery \\
\hline Steady-hand Eye robot [131] & Johns Hopkins University, US & Research prototype & retinal microsurgery \\
\hline M7 [181] & Stanford Research Institute, US & Research prototype & $\begin{array}{l}\text { RMIS for battlefield and space } \\
\text { applications }\end{array}$ \\
\hline MiroSurge [182] & German Aerospace Center, Germany & Research prototype & RMIS \\
\hline SOFIE [183] & $\begin{array}{l}\text { Technical University of Eindhoven, } \\
\text { the Netherlands }\end{array}$ & Research prototype & RMIS \\
\hline RAVEN II [41] & Applied Dexterity, US & Research prototype & RMIS \\
\hline
\end{tabular}

only general RMIS system available in the market (as of November 2015). It provides four arms for tool and camera handling. A newer version adapted for single-site MIS was introduced in 2011 [95]. The latest version $X i$ offers a larger workspace and enhanced vision quality. However, no haptic feedback is still provided to the user. A detailed technical analyses of the da Vinci robotic surgical system can be found at [96].

The majority of studies in the literature report that the absence of haptic feedback in MIS can be a cause of error and therefore a possible safety concern. In a study by Joice $e t$ al. [97] a modified observation-based Human Reliability Analysis (HRA) approach, was adopted to categorize errors encountered during the practice of minimally invasive cholecystectomy. The majority of the errors recorded were errors associated with the motor control of instruments where an inappropriate level of force was applied by the surgeon because of the diminished haptic feedback. The most serious consequence of the observed errors was the perforation of the gallbladder that occurred in 15 out of the 20 observed procedures. The role of force was again highlighted in a study of errors by 60 surgical trainees during simulated laparoscopic cholecystectomy on animal tissue [98]. Analysis revealed a total of 331 consequential errors from which $55 \%$ were due to application of excessive force. It must be noted that the role of haptic feedback in RMIS can be even more significant if the visual feedback is deteriorated during the RMIS operation, for example when the camera's view is clouded by fluids or by the smoke generated from the electrosurgical hook operations.

Notwithstanding the scarce quantity of conducted studies regarding the influence of haptic feedback in RMIS compared with that of traditional MIS (that is perhaps because of the lack of a commercially available RMIS systems with haptic feedback), the degree of evidence and conclusions are alike. Table II provides a list of clinical studies that have mentioned the lack of haptic feedback as an impediment to higher performances in various RMIS procedures. As it was reported by Bethea et al. [99], while working with minimally invasive robotic systems with no haptic feedback, even experienced surgeons often tear apart sutures and damage delicate tissues. In [100], Tavakoli et al. demonstrated that force interaction information can assist the user in exerting lower amount of forces on tissue during telemanipulated suturing maneuvers. In another quantitative study by Wagner $\mathrm{et} \mathrm{al}$. [101], subjects used a telerobotic system to perform a blunt dissection task and expose an artery in a synthetic model while viewing the operative site with a video laparoscope. Results show that presence of force feedback reduced the number of errors leading to tissue damage by a factor of three.

Demi, et al. [102] and Ortmaier et al. [103] used a prototypical force reflecting RMIS system to evaluate the importance of kinesthetic feedback in RMIS. They asked 25 surgeons to perform one manual MIS intervention and five robot-assisted intervention varying the scaling of the force feedback. The results included the comparison of outcomes in MIS, RMIS, and RMIS with force feedback. The study revealed that unintentional injuries were reduced in RMIS when appropriate force feedback is available. They reported however, that the operating time increased significantly in RMIS compared to a manual intervention. They hypothesized that the increase in time may be due to the delays in the position control loop of the robot that obliges the users to work slower to guarantee an accurate positioning of the instrument.

Some works in the literature have used the term "haptic feedback" for systems that provide only kinesthetic (force) feedback. As explained in section II, haptic feedback refers to the combination of both tactile and kinesthetic constituents that possess distinct properties. It is likely that this term misuse is due to the fact that most of research on haptics in surgical robotics has been focused on kinesthetic feedback. There is however no doubt on the importance of tactile perception in motor capabilities and mechanical property inspection. In fact, 
surgeons make ample use of their cutaneous senses in tissue palpation to differentiate tissue qualities. This can hardly be achieved with kinesthetic feedback alone, motivating some researchers to expend effort on enabling tactile feedback in surgical applications [104].

Excessive grasping forces and tissue slippage due to limited haptic feedback of traditional laparoscopic systems has been a concern of researchers [105] [106]. These are more likely to happen in systems such as the da Vinci, where the angular and force input of the user at the grip control of the robot's graspers is not proportional to the grasper instrument's output [107]. In some works, tactile feedback has been employed to prevent the user from applying excessive forces in tissue grasping with robotic laparoscopic instruments [108]. King et al. [109] fabricated and mounted a tactile feedback system on the da Vinci surgical robot allowing operators to grasp objects using the manipulators and to feel five discrete pressure levels on their digits that corresponded to the force applied at the grasper. Experiments comprised three blocks of peg transfer tasks performed by 20 subjects (4 surgeons), demonstrated a significant reduction of grip force during robotic manipulation with presence of tactile feedback in comparison with no-tactilefeedback interactions. In-vivo experimentation by 19 surgeons on porcine models for potential clinical implementation of tactile-feedback-equipped da Vinci robot was reported in [110]. The experiments demonstrated that tactile feedback significantly decreased grasping forces for both expert and novice surgeons. As a result, the overall incidence of tissue damage was significantly decreased in all subjects. The development and experimentation of a system is reported in [111] that provides high-frequency vibration cues during RMIS. The system measures the vibrations experienced by the instruments during surgery through accelerometers, and it uses voice coil actuators to recreate the measured vibrations for the surgeon at the master handles. Experimentation was conducted on 11 surgeons using an augmented da Vinci $\mathrm{S}$ to perform three in vitro manipulation tasks. Despite positive subjective evaluation from the surgeons, the results do not demonstrate significant difference in task performance with respect to RMS force, RMS acceleration, or completion time. Furthermore, the in vitro tasks included rigid object interactions that generate vibration cues which are often not encountered in soft tissue interaction. Nonetheless, based on an in-vivo evaluation of the system on a porcine model [112] and a recent experimentation with higher test population [113], it is concluded that instrument vibrations can increase the immersion and situational awareness of the surgeons in procedures and both surgeons and non-surgeons find this technology useful.

\section{B. Instrument Positioning}

In the field of hands-on robots where the user manually guides the surgical instrument fixed to the robotic assistant, interaction force perception depends on the robot's dynamics. The more "stiff" the robot is the more it deteriorates contact force perception, which can induce excessive tension. Impedance type controlled robots are better suited to provide low stiffness and damping [114]. Nevertheless, delicate forces such as those encountered in brain cortex stimulation are still likely to be masked by the residual inertia and friction of the manipulator.

Force scaling strategies were developed to address this problem [115]. Brain cortex stimulation encompasses the execution of a simple and repetitive gesture, i.e. target reaching, which is performed to ensure correct mapping of functional topography prior to, and during resection of a brain tumor or of an epileptogenic zone. With force scaling, the interaction forces generated by the contact with the soft tissue are increased to provide enhanced haptic perception to the user during surgical tool placement and therefore prevent over-tensioning the tissue. In a feasibility analysis, Beretta et al. [116] evaluated a torquebased impedance controller with force scaling for cooperatively assisted surgical brain cortex stimulation. 13 novice users and 8 neurosurgeons participated in the experiments involving a light weight robot LWR4+ (Kuka, Germany) and brainmimicking phantoms. Results showed an $80 \%$ reduction in tissue indentation overshooting for the novice users and $30 \%$ reduction in maximum indentation force by the surgeons, thus improving the safety level during tissue indentation. The

TABLE II

List OF CLINICAL STUdies MENTIONING THE LACK OF HAPTIC FEEDBACK AS A DRAWBACK IN RMIS

\begin{tabular}{|c|c|c|}
\hline Reference & Study & Discussion on Haptics \\
\hline$[184]$ & $\begin{array}{l}\text { Potential of performing coronary artery bypass } \\
\text { grafting with robot-assisted technology }\end{array}$ & $\begin{array}{l}\text { The absence of proper tactile or sensory feedback and inadequate visualization, } \\
\text { prolongs the time required to complete the task. }\end{array}$ \\
\hline$[185]$ & $\begin{array}{l}\text { Comparison of robotically performed and } \\
\text { traditional laparoscopic colorectal surgery }\end{array}$ & $\begin{array}{l}\text { Increase in operation time due to difficulties such as no haptic feedback (among } \\
\text { other difficulties). }\end{array}$ \\
\hline$[186]$ & $\begin{array}{l}\text { Randomized trial of robot-assisted versus } \\
\text { laparoscopic Nissen fundoplication }\end{array}$ & $\begin{array}{l}\text { Current robotic systems are not of significant benefit to routine surgical practice, } \\
\text { unless developments such as new instruments, smaller robotic arms and force } \\
\text { feedback are performed. }\end{array}$ \\
\hline [187] & $\begin{array}{l}\text { Review of clinical studies on robot-assisted } \\
\text { abdominal surgery }\end{array}$ & $\begin{array}{l}\text { One major drawback of robotic surgery is that the equipment does not supply the } \\
\text { surgeon with tactile sensation. Whether this technology will enjoy widespread } \\
\text { clinical application depends not only on its perceived cost-benefit profile but also } \\
\text { on future developments. }\end{array}$ \\
\hline$[188]$ & $\begin{array}{l}\text { Evaluation of robot-assisted Nissen } \\
\text { Fundoplication }\end{array}$ & $\begin{array}{l}\text { Addition of force feedback (among other improvements) may decrease the } \\
\text { operative time and make the procedure more attractive for anti-reflux surgery. }\end{array}$ \\
\hline [189] & $\begin{array}{l}\text { Review of clinical applications of robotic } \\
\text { technology in vascular and endovascular surgery }\end{array}$ & $\begin{array}{l}\text { Lack of force-feedback enhances the risk of vascular damage and perforation, } \\
\text { because a certain amount of stiffness of the active steerable catheter is required for } \\
\text { navigation and orientation. }\end{array}$ \\
\hline
\end{tabular}


significant difference in the levels of improvement between novice users and surgeons highlights the importance of performing evaluation by expert users, as it was discussed in the subsection III-C.

\section{Needle Insertion}

One of the most common procedures in modern clinical practice is insertion of needles and catheters, where long, slender surgical tools and needles are inserted into soft, inhomogeneous tissue to reach a target inside the body. Such procedures range in complexity from superficial needle sticks to the biopsy of deep-seated tumors. In the absence of real-time imaging, the clinician cannot observe the path of the needle inside the tissue and thus must rely solely on kinesthetic feedback from the tool, correlated with their own mental visualization of anatomic structures to estimate the needle's current position with respect to preoperative medical images. Perceiving the needle interaction forces could allow the surgeon to better estimate the position of the needle inside the tissue, enhance the accuracy in soft tissue identification (e.g., differentiating a vessel in brain parenchyma during probe/electrode placement for deep brain stimulation) and therefore contribute to significant safety improvements [117]. Gerovichev et al. [118] evaluated the effect of visual and haptic feedback in needle insertion tasks. Using a virtual needle insertion simulator, they studied the detection of transition between different layers (skin, fat and muscle) with two groups of volunteers. First group with 10 volunteers had medium exposure to haptic interfaces and low exposure to real needle insertion and the second group 4 volunteers with extensive experience in real needle insertion and no experience in haptics. The results show that the addition of force feedback reduces error in detection of transitions between tissue layers by 55\% and as it can be expected, the addition of real-time visual feedback improved user performance by $87 \%$. The authors of [118] discussed the results of their experiments as a study of force feedback in telerobotic needle insertion. However, the conclusion can be extended to cooperative robotic needle insertion where the haptic feedback can be severely distorted by the dynamics of the robot arm.

A particular challenge in using force information in needle insertion is that the interaction with tissue is mediated by the needle and the force feedback on the grip includes both tip contact force and frictional forces between the tissue and the needle shaft [119]. In many cases, attempts were made to enhance the perception by identifying the mechanical model of the tissue and estimating the tip force through subtraction of the modeled force from the total measured force [120], [121]. Other researchers chose to follow a model free approach. Kataoka et al. [122] proposed an instrumented coaxial needle that separately measured pressing/cutting force at the needle tip and shear friction on the needle shaft, using two different force sensors. Based on the coaxial needle scheme, De Lorenzo et al. [123] presented a cooperative robotic assistant with the purpose of improving operator's perception of small variations in tissue properties during needle insertion. Benefiting from separate measurements of the shaft and tip forces, the control algorithm can display the latter to the operator. The system was tested through experiments on brain-mimicking samples by 11 users who were asked to blindly insert the robot-assisted biopsy needle into the sample and press a button as soon as they perceived hitting a membrane. The results showed that the coaxial needle assistant facilitates the perception of membranes during the needle insertion. However, an amplification of the force at the needle tip was required. The success rate of the robot-assisted needle with amplified tip force was significantly higher. This, as authors of [123] argue, is due to the higher ratio of the shear force to the tip force in these cases and the fact that in presence of large background loads, small force variations are not felt by the human operator.

\section{Palpation and tissue stiffness mapping}

Thorough assessment of an organ's mechanical properties relies heavily on tactile feedback, especially when layers of healthy tissue cover the abnormalities. Palpation probes aim at restituting this capability to the operators of surgical robotic systems. Konstantinova et al. [124] have recently (2014) surveyed tactile sensing for palpation in RMIS, discussing manual techniques used in palpation by expert surgeon and common designs of palpation probes. The ongoing research primarily revolves around performance enhancement and cost reduction through novel designs or new implementations. In [125], a multi-fingered pneumatic haptics device is proposed, aiming at haptic stimulation of multiple fingers for remote soft tissue palpation. Evaluation by 9 non-expert users through palpation in a virtual environment seems to suggest improvement in stiffness levels discrimination, compared to that of single finger stimulation. In [126] a haptic palpation probe is introduced for locating subcutaneous blood vessels. The simple design of the probe reduces its production cost, making the sensor disposable. The efficacy of the sensor is demonstrated through sliding indentation experiments on silicone-based tissue phantom.

Given that most of MIS palpation devices are at the stage of research and design, not many clinical studies are available in the literature. A particularity of this field is that, as the mechanical property of tissues can differ in living conditions from that of ex-vivo tissues, experimentation on ex-vivo models may produce limited results. However, only devices that have a high level of robustness and safety can be approved for in-vivo trials. In an initial study, Åstrand et al. [127] employed a tactile resonance sensor to detect tumors of a fresh prostate gland exvivo, from a radical prostatectomy patient. The measurements on the prostate was in agreement with the location of the histologically determined cancer tumors. Although this initial results are promising, further investigation is required to quantitatively assess the accuracy and reliability of the sensor. Pacchierotti et al. [128], added a tactile sensor to the tool of a standard Da Vinci system and a cutaneous display to it's master controller to convey contact deformations to the user through constant pressure and vibration. Although the deformation feedback results show improvements in palpation performance, for the vibration feedback the results are not conclusive.

Another trend in palpation research is to create tissue models 
by acquiring organ's stiffness distribution using rolling indentation probes [129]. The recorded information can be visualized for soft tissue tumor detection. Since the mechanical properties of the tissue are measured, it is possible to reconstruct the tissue model in a virtual environment with haptic feedback for the surgeon to perform palpation on [130]. The aim of these approaches is to eliminate the possibility of experiencing instability due to inherent characteristics of direct force feedback discussed in section III. While these methods provide an alternative for cases where palpation is necessary and stability of direct force feedback cannot be guaranteed, the feasibility in terms of added operation time should be studied and eventually evaluated in clinical trials.

\section{E. Microsurgical Tasks}

Microsurgery requires manipulation in submillimeter scale while visualizing the surgical field through a microscope with 20 to 30 times magnification. A variety of surgical fields require microsurgery, such as neurosurgery, ophthalmic surgery and reconstructive surgery [131]. Development of experimental systems for microsurgery started in the late 90s. Examples include master-slave systems such as the Robot-Assisted MicroSurgery (RAMS) workstation [132], NeuRobot [133] and cooperative type robots like the steady-hand eye robot [134]. Among special microsurgical applications, ophthalmic microsurgery, such as vitreo-retinal surgery, are very demanding procedures due to extremely small cutting forces and minute workspace that require advanced surgical skills that are near, if not beyond, human capabilities [135]. A typical task is epiretinal membrane peeling, where an instruments with micro-forceps is inserted through a scleral trocar and the semitransparent membrane is peeled off the retina, to restore a patient's vision. As it is often the case in microsurgery, the interaction forces involved are well below the human sensory perception. In such an operation, applying forces higher than the strength of the retina tissue, raises the risk of hemorrhage and retina tearing. Here, providing an amplified interaction force can allow the user to perceive and safely apply delicate forces that are traditionally interpreted solely from optical feedback [136][137]. Balicki et al. [138] demonstrated the efficacy of providing tool tip interaction force feedback, using force sensing instrument that incorporate fiber optic sensors into the distal portion of the instrument shaft located inside the eye. The experiments were however performed on a single user. Later He et al. [139] extended the work by adding an additional force sensor to a variable admittance controlled cooperative robot, to provide force feedback from both tool tip and sclera entry point. The work was based on the idea that in freehand manipulation, the surgeon can often sense the contact force at the sclera entry point, and utilizes it as an indicator to guide the desired motion. The results of a 5-trial experimentation show improvements in precision and force minimization in sclerotomy. It must be noted however, that providing direct force feedback is not the only approach taken by researchers for reducing applied force in retinal membrane peeling. In [140] for example, an active handheld micromanipulator [141] is implemented under a hybrid position/force control schema that is shown to reduce the maximum force by more than $50 \%$ in experiments on both artificial and animal models.

Table III, summarizes the research studies that have investigated the effects of haptic feedback in robot-assisted surgery.

\section{Haptics IN SimUlation FOR SURGICAL TRAINING}

The introduction of laparoscopic surgery was followed by a rapidly growing demand of surgical skills training. The techniques were new to the general surgeons and they had little, if any, training and experience with laparoscopy. Apart from lectures, discussions, and demonstrations, it was only practical exercise that could equip the surgeons with the set of psychomotor skills that underlie surgical techniques. Live animals were used for practical exercises in the early years [142]. However due to ethical issues and costs, laparoscopic simulators were developed using inanimate box trainers and shown to be effective [143] [144]. Computer-based Virtual Reality (VR) platforms made a bigger impact on the medical community and currently are a state-of-the-art technique in medical training systems. With VR it is possible to train psychomotor skills by consequence-free simulated tasks that vary from basic laparoscopic exercises to full operative procedures. A substantial progress in the learning curve can be achieved by using repetitive VR tasks before starting the practice on patients [145] [89]. Moreover, computer-based VR training offers means of providing objective performance assessment during and after training that can accelerate the learning process [146].

Despite the reported success of VR simulators in improving MIS operating room performance [147], augmented RMIS skill learning [148]-[150] and cost reduction [151], the lack of haptic feedback in some simulators may be considered as a potential drawback. Although there is no consensus on the benefits of haptic feedback in VR training for MIS [152], the majority of the conducted studies suggest that realistic procedural simulations with haptic feedback lead to better performances and more rapid learning curves, [106][25][153]. Jacobs et al. [88] studied the impact of haptic-visual over visual-only passive training for RMIS using two da Vinci consoles. Results suggested enhancement in terms of number of errors, accuracy and completion time in haptic-visual training group.

Some virtual reality simulators such as the $d V$-Trainer (Mimic Technologies, Washington, USA) have been developed and commercialized for the $d a$ Vinci surgical system. The $d V$ Trainer is a 2-handed haptic system with 3 degrees of force feedback and 7 degrees of measurements (translation, rotation, and grip closure) for each hand. Kenney et al. [154] validated the simulation system by performing experiments with 11 residents and 5 surgeons. In a study by Lerner et al. [155] training with the learning performance with $\mathrm{dV}$-Trainer was compared to that of training with the actual da Vinci system. Two groups of trainees and residents participated in the experiments. In one group, each participant completed one session of five exercises on the actual robotics system that were scored for timing and accuracy, followed by four training sessions on the simulator, and concluded with a final session on 
TABLE III

LIST OF RESEARCH STUDIES ON EFFECTS OF HAPTIC FEEDBACK IN ROBOT-AsSISTED SURGERY

\begin{tabular}{|c|c|c|c|}
\hline Procedure & Ref. & Study & Results \\
\hline \multirow[t]{8}{*}{ RMIS } & [99] & $\begin{array}{l}\text { Application of haptic feedback to robotic } \\
\text { knot tying }\end{array}$ & $\begin{array}{l}\text { Significantly more consistent tensions applied to suture materials, without } \\
\text { breakage, during robotic knot tying enhanced with haptic feedback compared to } \\
\text { knots tied without feedback. }\end{array}$ \\
\hline & [90] & $\begin{array}{l}\text { Haptic feedback and sensory substitution } \\
\text { on RMIS suturing forces }\end{array}$ & $\begin{array}{l}\text { Force interaction information can assist the user in exerting lower amount of } \\
\text { forces on tissue during telemanipulated suturing maneuvers. }\end{array}$ \\
\hline & {$[101]$} & Force feedback in blunt dissection & $\begin{array}{l}\text { Presence of force feedback reduced the number of errors leading to tissue } \\
\text { damage by a factor of three. }\end{array}$ \\
\hline & $\begin{array}{l}{[92],} \\
{[93]}\end{array}$ & $\begin{array}{l}\text { Kinesthetic feedback in RMIS by } \\
\text { comparison of MIS, RMIS, and RMIS + } \\
\text { force feedback. }\end{array}$ & $\begin{array}{l}\text { Unintentional injuries were reduced in RMIS when appropriate force feedback } \\
\text { is available. }\end{array}$ \\
\hline & [94] & $\begin{array}{l}\text { Force feedback and sensory substitution in } \\
\text { tissue differentiation }\end{array}$ & $\begin{array}{l}\text { Subjects were more comfortable and more accurate at characterizing tissues } \\
\text { with simultaneous vision and force feedback compared with vision feedback } \\
\text { alone or force feedback alone. }\end{array}$ \\
\hline & [96] & $\begin{array}{l}\text { Haptic feedback and sensory substitution } \\
\text { in tissue grasping force }\end{array}$ & $\begin{array}{l}\text { A significant reduction of grip force during robotic manipulation with presence } \\
\text { of tactile feedback in comparison with no-tactile-feedback interactions. }\end{array}$ \\
\hline & [110] & $\begin{array}{l}\text { Potential clinical implementation of } \\
\text { tactile-feedback-equipped da Vinci robot }\end{array}$ & $\begin{array}{l}\text { The experiments demonstrated that tactile feedback significantly decreased } \\
\text { grasping forces for both expert and novice surgeons. }\end{array}$ \\
\hline & [111] & $\begin{array}{l}\text { Providing high-frequency vibration cues in } \\
\text { RMIS }\end{array}$ & $\begin{array}{l}\text { Despite positive subjective evaluation from the surgeons, the results did not } \\
\text { demonstrate significant difference in task performance }\end{array}$ \\
\hline $\begin{array}{l}\text { Instrument } \\
\text { positioning }\end{array}$ & [99] & $\begin{array}{l}\text { Force enhancement for hands-on surgical } \\
\text { brain cortex stimulation }\end{array}$ & $\begin{array}{l}\text { Force enhancement resulted in } 80 \% \text { reduction in tissue indentation overshooting } \\
\text { for novice users and } 30 \% \text { reduction in max. indentation force by the surgeons. }\end{array}$ \\
\hline \multirow{2}{*}{$\begin{array}{l}\text { Needle } \\
\text { insertion }\end{array}$} & {$[101]$} & $\begin{array}{l}\text { Visual and haptic feedback in simulated } \\
\text { needle insertion tasks }\end{array}$ & $\begin{array}{l}\text { The addition of force feedback reduces error in detection of transitions between } \\
\text { tissue layers by 55\%. }\end{array}$ \\
\hline & [105] & $\begin{array}{l}\text { Force enhancement in hands-on needle } \\
\text { insertion }\end{array}$ & $\begin{array}{l}\text { The success rate of membrane hitting perception was significantly higher when } \\
\text { the robot-assisted needle with amplified tip force was implemented. }\end{array}$ \\
\hline Palpation & {$[125]$} & Multi-fingered pneumatic haptic device & $\begin{array}{l}\text { Improvement in stiffness level discrimination, compared to that of single finger } \\
\text { stimulation. }\end{array}$ \\
\hline \multirow[t]{2}{*}{ Microsurgery } & [113] & $\begin{array}{l}\text { Tooltip force enhancement in robotic } \\
\text { membrane peeling for vitreoretinal surgery }\end{array}$ & $\begin{array}{l}\text { Force scaling yielded the best overall performance in terms of mean forces } \\
\text { showing the efficacy of providing tool tip interaction force feedback. }\end{array}$ \\
\hline & [114] & $\begin{array}{l}\text { Multi point force sensing for RMIS in } \\
\text { retinal microsurgery }\end{array}$ & $\begin{array}{l}\text { Improvements in precision and force minimization in sclerotomy. } \\
\text { Successful retina vein tracing in an eye phantom with the introduced approach. }\end{array}$ \\
\hline
\end{tabular}

the robot in which the initial exercises were repeated. Improvement on the exercises of this group was compared with the other group who completed four to six training sessions using the same exercises on the robotic system without any simulator training. It is claimed that training on the $\mathrm{dV}$-Trainer improved performance on the robot system equal to training with the robot itself.

Force modelling and simulation of needle insertion has been a very active topic of research that aim to prevent complications caused by poor technique and needle placement. In works such as [156] devices were developed to measure instrument-tissue interaction forces and other contact properties by ex vivo and in vivo experiments. Data acquired by these works can be used to model more accurately tissue interaction forces in virtual environment. A number of researchers have developed haptic virtual environments for surgical simulation, for many procedures including catheter insertion, bone cutting in middle ear surgery [157], brachytherapy [158], lumbar puncture[159], and endoscopic surgeries [160].

With the rapid development of haptically enabled robotic systems, it should be possible in the near future to develop realistic simulations with haptic feedback that not only will allow novice clinicians to learn surgical procedures more efficiently, but also enable expert surgeons to prepare for complex and particular procedures prior to the actual operation. A review on medical and surgical simulation systems can be found in [161].

\section{SENSORY SUBSTITUTION}

In view of current limitations in haptic sensing and control technologies that render providing direct haptic feedback for clinical application challenging, research on sensory substitution has received a lot of attention. Relying on the adaptive capacities of the central nervous system (brain plasticity), sensory substitution compensates human sensory loss by coupling information from different sensory channels to brain (e.g. Braille tactile writing system for the visually impaired) [162]. In teleoperation, sensory substitution often refers to transmission of environmental information by engaging another sensory channel rather than providing kinesthetic feedback on the master site. The typical substitutes for kinesthetic feedback are visual, auditory and tactile displays. Since implementing these passive displays devices does not require active actuation of the master device, the risk of facing instability is dramatically reduced. Tactile displays are more complex to employ than visual or auditory devices. However, as Hayward [163] has discussed, they possess properties that can be exploited to trick a human into perceiving force cues without providing actual force feedback. Experiments such as those performed by Prattichizzo et al. [164] and Meli et al. [165], suggest that users are able to perceive kinesthetic feedback (e.g., presence of a virtual wall) 
thanks to tactile feedback only. Auditory and visual signals can be effective in providing the operator with simple haptic information. Kitagawa et al.[166] compared applied forces during a standardized surgical knot-tying task with the $d a$ Vinci under 4 different sensory-substitution scenarios: no feedback, auditory feedback, visual feedback, and combined auditoryvisual feedback. The feedbacks provided also a means of comparison to an ideal tension that was defined from previous measurements. They report that the user performance of robotassisted suture tying aided by visual feedback or combined auditory-visual feedback sensory substitution was comparable and even superior to performances of tying directly with hands. Similarly, Akinbiyi et al. [167] report a decrease in the number of broken sutures in a phantom knot tying task, and Tavakoli et al. [168] report better localization accuracy for a lump localization task when force levels were visually communicated to the operator.

While providing visual or auditory feedbacks are shown to enhance performance in such simple tasks, it must be noted that they may not be as effective for complex tasks due to perceptive and cognitive overload [169]. In visual feedback particularly, it is more practical to use peripheral vision capabilities of the user (e.g. Shoval et al [170]) rather than overlaying distracting information on the visual channel. Nonetheless, the amount of information that can be communicated by visual/auditory sensory substation is limited and force feedback is a more intuitive medium of relaying haptic information to the user.

\section{ACTIVE CONSTRAINTS}

An active constraint (introduced as "virtual fixture" by Rosenberg [171]) is a software generated constraint that attempts to force a robot's motion along desired paths or prevent a robot from moving into forbidden regions, providing the potential benefit of safer and faster operation. Davies et al. used the term "active constraints" for hands-on robot-assisted knee replacement surgery [172], where the surgical tools attached to a back-drivable robotic arm was manually operated by the surgeon. The robot showed little resistance when the tool was in allowed regions. However, as the surgeon moved toward forbidden regions (e.g. tissue which should not be removed), the stiffness in that direction increased to prevent damage. Abbott and Okamura [173] tested various forbidden region constraints and four control architectures in teleoperation using a one DoF master/slave system. Bettini et al. [174] presented a vision-based system for hands-on manipulation at millimeter to micrometer scales using the Steady Hand Eye robot. Results showed an expected trade-off between user performance and control; i.e. harder constraints resulted in higher accuracy and shorter execution time by highly limiting the user's ability to control the motion. Nevertheless, they reported an overall improvement even in the case of less limiting constraints. Yamamoto et al. [175] developed an interface for teleoperated RMIS providing vision-based Forbidden-Region Virtual Fixtures (FRVF) and augmented visual feedback. The interface was tested through two tasks, namely palpation to detect hard lumps and surface tracing performed on artificial prostate model. Experiments showed the effectiveness of the FRVFs to prevent penetration into the curved surface of the artificial prostate model. Readers interested in technical aspects of active constraint implementation are referred to a recent survey by Bowyer et al. dedicated to this subject [15].

A current obstacle in implementation of active constraints in surgical applications is the organs' displacement and deformability. Whether the constraint's geometry is defined pre-operatively or intra-operatively, it must be mapped correctly to the organs as they move or deform. This can be a demanding task, particularly in cases where the surgical targets have few structural features for tracking. For rigid organs, such difficulties are less encountered and therefore orthopedic robotic surgery is one of the few cases in which active constraints are currently used in clinical applications. Recent works including operations on cadavers [176] and comparative retrospective study on 206 patients in Unicompartmental Knee Arthroplasty (UKA) [177], suggest improvements in accurate prosthesis positioning. A prospectively randomized study of robot-assisted Total Knee Arthroplasty (TKA) on 60 patients [5] concluded that robot-assisted TKA ammends mechanical alignment. However, the study did not show any significant differences in terms of clinical outcomes at 6-month early follow-up.

Active constraints are one of the most promising features of haptically enabled surgical robots. Future directions in this field include improving constraint construction from medical imaging modalities, enhancement in intra-operative registration and tracking methods for dynamic situations, studying subjective aspects of constraint enforcement and performance metric evaluation. As commercial surgical robots with haptic capabilities are soon to appear, it can only be expected to see more research efforts expended in this field.

\section{CONCLUSION}

This paper presented an overview on challenges and benefits of haptic technologies in surgical robotics application. In addition to experimental publications, available clinical studies that involve haptically enabled surgical systems were reviewed. These works, some with high level of evidence and others with lower levels, show the benefits of including haptic feedback in specific applications. Surgical robotics is still struggling to prove itself useful in the operating room. Although initial reports on patient outcomes yielded mixed results, as more medical centers adopt robotics programs, comparable if not improved outcomes emerge for some applications. Robot technologists and lead users need to provide clear evidence of clinical benefits to convince medical system procurers and surgeons, to adopt robot-assisted systems despite of their cost and complexity. However, showing an improvement in outcomes and cost effectiveness is not always trivial. Particularly, for surgical robotic research groups and companies to survive and reach the market, justification of the use of robots must involve claiming clear measures, rather than long-term statistical measures that may require years of costly study. Incorporation of haptic technologies in surgical robotic systems can have a significant effect on the uptake of these systems, convincing also the more restive surgeons. The point is not that 
haptic feedback is absolutely indispensable and surgical operations cannot be robotically performed without it, but what advantages can be achieved in such tasks by employing this underutilized sensory channel. This has motivated the considerable quantity of research conducted in this field to improve hardware (haptic displays with higher power and frequency response and lower inertia and friction and force/tactile sensors that are high-performance, low-cost, biocompatible and sterilizable), software (more advanced and robust control systems to tackle challenges of stability and transparency) and to introduce innovative methods in employing the haptic sensory channel to enhance surgical outcomes. Despite remaining hurdles, the wide diffusion of surgical robots, will foster the research towards innovations that can change the robotics and surgical landscapes in the next decade.

\section{REFERENCES}

[1] A. M. O. Hannaford, Blake, "Haptics," in Springer Handbook of Robotics., B. Siciliano and O. Khatib, Eds. Berlin, Heidelberg: Springer Berlin Heidelberg, 2008, pp. 719-739.

[2] K. MacLean and V. Hayward, "Do it yourself haptics: Part ii," IEEE Robot. Autom. Mag., no. March, 2008.

[3] Y.S. Kwoh, J. Hou, E. a. Jonckheere, and S. Hayati, "A robot with improved absolute positioning accuracy for CT guided stereotactic brain surgery," IEEE Trans. Biomed. Eng., vol. 35, no. 2, pp. 153160, 1988 .

[4] H. G. Kenngott, L. Fischer, F. Nickel, J. Rom, J. Rassweiler, and B. P. Müller-Stich, "Status of robotic assistance - A less traumatic and more accurate minimally invasive surgery?," Langenbeck's Arch. Surg., vol. 397, no. 3, pp. 333-341, 2012.

[5] M. H. L. Liow, Z. Xia, M. K. Wong, K. J. Tay, S. J. Yeo, and P. L. Chin, "Robot-assisted total knee arthroplasty accurately restores the joint line and mechanical axis. A prospective randomised study.," $J$. Arthroplasty, vol. 29, no. 12, pp. 2373-7, Dec. 2014.

[6] G. I. Barbash and S. A. Glied, "New Technology and Health Care Costs -- The Case of Robot-Assisted Surgery," N. Engl. J. Med., vol. 363, no. 8, pp. 701-704, 2010.

[7] C. Bolenz, A. Gupta, T. Hotze, R. Ho, J. A. Cadeddu, C. G. Roehrborn, and Y. Lotan, "Cost comparison of robotic, laparoscopic, and open radical prostatectomy for prostate cancer.," Eur. Urol., vol. 57, no. 3, pp. 453-8, Mar. 2010

[8] W. Korb, R. Marmulla, J. Raczkowsky, J. Mühling, and S. Hassfeld, "Robots in the operating theatre - Chances and challenges," Int. J. Oral Maxillofac. Surg., vol. 33, no. 8, pp. 721-732, 2004.

[9] G. H. Ballantyne, "Robotic surgery, telerobotic surgery, telepresence, and telementoring. Review of early clinical results.," Surg. Endosc., vol. 16 , no. 10 , pp. 1389-402, Oct. 2002.

[10] D. B. Camarillo, T. M. Krummel, and J. K. Salisbury, "Robotic technology in surgery: Past, present, and future," Am. J. Surg., vol. 188, no. 4 SUPPL. 1, pp. 2-15, 2004.

[11] L. Adams, W. Krybus, D. Meyer-Ebrecht, R. Rueger, J. M. Gilsbach, R. Moesges, and G. Schloendorff, "Computer-assisted surgery," IEEE Comput. Graph. Appl., vol. 10, no. 3, pp. 43-51, May 1990.

[12] E. De Momi and G. Ferrigno, "Robotic and artificial intelligence for keyhole neurosurgery: the ROBOCAST project, a multi-modal autonomous path planner," Proc. Inst. Mech. Eng. Part H J. Eng. Med., vol. 224, no. 5, pp. 715-727, May 2010.

[13] R. H. Taylor, B. D. Mittelstadt, H. a. Paul, W. Hanson, P. Kazanzides, J. F. Zuhars, B. Williamson, B. L. Musits, E. Glassman, and W. L. Bargar, "Image-directed robotic system for precise orthopaedic surgery," IEEE Trans. Robot. Autom., vol. 10, no. 3, pp. 261-275, 1994.

[14] J. R. Adler, S. D. Chang, M. J. Murphy, J. Doty, P. Geis, and S. L. Hancock, "The Cyberknife: A frameless robotic system for radiosurgery," Stereotact. Funct. Neurosurg., vol. 69, no. 1-4, pp. 124-128, 1997.

[15] A. Murali, S. Sen, B. Kehoe, A. Garg, S. Mcfarland, S. Patil, W. D. Boyd, S. Lim, P. Abbeel, and K. Goldberg, "Learning by Observation for Surgical Subtasks: Multilateral Cutting of 3D Viscoelastic and 2D Orthotropic Tissue Phantoms," Int. Conf. Robot. Autom., pp. 12021209, 2015.

[16] M. H. P. H. van Beurden, W. A. IJsselsteijn, and J. F. Juola, "Effectiveness of stereoscopic displays in medicine: A review," $3 D$ Res., vol. 3, no. 1, p. 3, Jan. 2012.

[17] A. Okamura, "Methods for haptic feedback in teleoperated robotassisted surgery," Ind. Robot An Int. J., vol. 31, no. 6, pp. 499-508, 2004.

[18] M. J. Massimino and T. B. Sheridan, "Sensory substitution for force feedback in teleoperation," Presence, vol. 2, no. 4, pp. 344-352, 1994.

[19] P. S. Green, J. W. Hill, J. F. Jensen, and A. Shah, "Telepresence surgery," IEEE Eng. Med. Biol. Mag., vol. 14, no. 3, pp. 324-329, 1995.

[20] L. B. Rosenberg, "Virtual fixtures: Perceptual tools for telerobotic manipulation," Proc. IEEE Virtual Real. Annu. Int. Symp., pp. 76-82, 1993

[21] S. A. Bowyer, B. L. Davies, and F. Rodriguez y Baena, "Active Constraints/Virtual Fixtures: A Survey," IEEE Trans. Robot., vol. 30, no. 1, pp. 138-157, Feb. 2014.

[22] A. Liu, F. Tendick, K. Cleary, and C. Kaufmann, "A survey of surgical simulation: applications, technology, and education," Presence, vol. 12, no. 6, pp. 599-614, 2003.

[23] A. G. Gallagher, E. M. Ritter, H. Champion, G. Higgins, M. P. Fried, G. Moses, C. D. Smith, and R. M. Satava, "Virtual reality simulation for the operating room: proficiency-based training as a paradigm shift in surgical skills training.," Ann. Surg., vol. 241, no. 2, pp. 364-372, 2005.

[24] E. P. Westebring-van der Putten, R. H. M. Goossens, J. J. Jakimowicz, and J. Dankelman, "Haptics in minimally invasive surgery--a review.," Minim. Invasive Ther. Allied Technol., vol. 17, no. 1, pp. 3-16, 2008.

[25] O. a J. Van Der Meijden and M. P. Schijven, "The value of haptic feedback in conventional and robot-assisted minimal invasive surgery and virtual reality training: A current review," Surg. Endosc. Other Interv. Tech., vol. 23, no. 6, pp. 1180-1190, 2009.

[26] A. A. A. Hamed, S. C. Tang, H. Ren, C. Payne, K. Masamune, G. Tang, A. Squires, J. Mohammadpour, and Z. T. H. Tse, "Advances in Haptics, Tactile Sensing, and Manipulation for Robot-Assisted Minimally Invasive Surgery, Noninvasive Surgery, and Diagnosis," J. Robot., vol. 2012, pp. 1-14, 2012.

[27] E. B. Vander Poorten, E. Demeester, and P. Lammertse, "Haptic feedback for medical applications, a survey," Actuator, pp. 1-6, 2012.

[28] A. M. Okamura, "Haptic Feedback in Robot-Assisted Minimally Invasive Surgery," Curr. Opin. Urol., vol. 19, no. 1, pp. 102-107, 2009.

[29] M. Benali-Khoudja, "Tactile interfaces: a state-of-the-art survey," Int. Symp. Robot., vol. 31, pp. 23-26, 2004.

[30] L. Dipietro, A. M. Sabatini, and P. Dario, "A Survey of Glove-Based Systems and Their Applications," IEEE Trans. Syst. Man, Cybern. Part C (Applications Rev., vol. 38, no. 4, pp. 461-482, Jul. 2008.

[31] S. D. Laycock and a. M. Day, "Recent developments and applications of haptic devices," Comput. Graph. Forum, vol. 22, no. 2, pp. 117-132, 2003.

[32] R. J. Stone, "Haptic feedback: A brief history from telepresence to virtual reality," Haptic Human-Computer Interact., pp. 1-16, 2001.

[33] V. Hayward, O. R. Astley, M. Cruz-Hernandez, D. Grant, and G. Robles-De-La-Torre, "Haptic interfaces and devices," Sens. Rev., vol. 24, no. 1, pp. 16-29, 2004.

[34] M. Hafez, "Tactile interfaces: Technologies, applications and challenges," Vis. Comput., vol. 23, no. 4, pp. 267-272, 2007.

[35] A. Talvas, M. Marchal, and A. Lecuyer, "A Survey on Bimanual Haptic Interaction," IEEE Trans. Haptics, vol. 1412, no. c, pp. 1-1, 2014.

[36] J. K. S. Thomas H. Massie, "The PHANToM haptic interface: A device for probing virtual objects."

[37] "Novint Falcon." [Online]. Available: www.novint.com/index.php/novintfalcon. [Accessed: 17-Jun-2015].

[38] "Products: Force Dimention." [Online]. Available: http://www.forcedimension.com/products. [Accessed: 17-Jun-2015].

[39] A. Simorov, R. S. Otte, C. M. Kopietz, and D. Oleynikov, "Review of surgical robotics user interface: what is the best way to control robotic surgery?," Surg. Endosc., vol. 26, no. 8, pp. 2117-2125, 2012. 
[40] B. Hannaford, J. Rosen, D. W. Friedman, H. King, P. Roan, L. Cheng, D. Glozman, J. Ma, S. N. Kosari, and L. White, "Raven-II: An open platform for surgical robotics research," IEEE Trans. Biomed. Eng., vol. 60 , no. 4, pp. 954-959, 2013.

[41] M. Jakopec, S. J. Harris, F. Rodriguez y Baena, P. Gomes, and B. L. Davies, "The Acrobot $₫$ system for total knee replacement," Ind. Robot An Int. J., vol. 30, no. 1, pp. 61-66, Feb. 2003.

[42] R. H. Taylor and D. Stoianovici, "Medical Robotics in ComputerIntegrated Surgery," IEEE Trans. Robot. Autom., vol. 19, no. 5, pp. 765-781, 2003.

[43] R. a. Beasley, "Medical Robots: Current Systems and Research Directions," J. Robot., vol. 2012, pp. 1-14, 2012.

[44] P. Kazanzides, G. Fichtinger, G. D. Hager, A. M. Okamura, L. L. Whitcomb, and R. H. Taylor, "Surgical and Interventional Robotics: Core Concepts, Technology, and Design.," IEEE Robot. Autom. Mag., vol. 15, no. 2, pp. 122-130, 2008.

[45] G. Dogangil, B. L. Davies, and F. Rodriguez y Baena, "A review of medical robotics for minimally invasive soft tissue surgery.," Proc. Inst. Mech. Eng. H., vol. 224, no. 5, pp. 653-679, 2010.

[46] P. Gomes, "Surgical robotics: Reviewing the past, analysing the present, imagining the future," Robot. Comput. Integr. Manuf., vol. 27, no. 2, pp. 261-266, 2011.

[47] T. a. Mattei, A. H. Rodriguez, D. Sambhara, and E. Mendel, "Current state-of-the-art and future perspectives of robotic technology in neurosurgery," Neurosurg. Rev., vol. 37, no. 3, pp. 357-366, 2014.

[48] M. Hoeckelmann, I. J. Rudas, P. Fiorini, F. Kirchner, and T. Haidegger, "Current Capabilities and Development Potential in Surgical Robotics," Int. J. Adv. Robot. Syst., p. 1, 2015.

[49] D. Whitney, "Historical perspective and state of the art in robot force control," Proceedings. 1985 IEEE Int. Conf. Robot. Autom., vol. 2, pp. 262-268, 1985.

[50] T. B. Sheridan and W. R. Ferrell, "Remote Manipulative Control with Transmission Delay," IEEE Trans. Hum. Factors Electron., vol. HFE-4, no. 1, pp. 25-29, 1963.

[51] T. B. Sheridan, "Space teleoperation through time delay: Review and prognosis," IEEE Trans. Robot. Autom., vol. 9, no. 5, pp. 592-606, 1993.

[52] R. J. Anderson and M. W. Spong, "Bilateral control of teleoperators with time delay," IEEE Trans. Automat. Contr., vol. 34, no. 5, pp. 494-501, May 1989.

[53] G. Niemeyer and J. J. E. Slotine, "Stable adaptive teleoperation," IEEE J. Ocean. Eng., vol. 16, no. 1, pp. 152-162, 1991.

[54] M. V. Charles A. Desoer, Feedback systems: input-output properties. New York: Academic Press, 1975.

[55] N. Hogan, "Controlling impedance at the man/machine interface," Proceedings, 1989 Int. Conf. Robot. Autom., 1989.

[56] M. Minsky, O. Ming, O. Steele, F. P. Brooks, and M. Behensky, "Feeling and seeing: issues in force display," ACM SIGGRAPH Comput. Graph., vol. 24, no. 2, pp. 235-241, 1990.

[57] R. Gillespie and M. Cutkosky, "Stable user-specific haptic rendering of the virtual wall," Proc. ASME Int. ..., 1996.

[58] J. E. Colgate and J. M. Brown, "Factors affecting the Z-Width of a haptic display," Proc. 1994 IEEE Int. Conf. Robot. Autom., pp. 32053210, 1994.

[59] J. Abbott and A. Okamura, "Effects of position quantization and sampling rate on virtual-wall passivity," Robot. IEEE Trans., vol. 21, no. 5, pp. 952-964, 2005.

[60] J. E. Colgate, P. E. Grafing, M. C. Stanley, and G. Schenkel, "Implementation of stiff virtual walls in force-reflecting interfaces," Proc. IEEE Virtual Real. Annu. Int. Symp., pp. 202-208, 1993.

[61] J. E. Colgate, M. C. Stanley, and J. M. Brown, "Issues in the haptic display of tool use," Proc. 1995 IEEE/RSJ Int. Conf. Intell. Robot. Syst. Hum. Robot Interact. Coop. Robot., vol. 3, pp. 140-145, 1995.

[62] C. B. Zilles and J. K. Salisbury, "A constraint-based god-object method for haptic display," in Proceedings 1995 IEEE/RSJ International Conference on Intelligent Robots and Systems. Human Robot Interaction and Cooperative Robots, 1995, vol. 3, pp. 146151.

[63] R. J. Adams and B. Hannaford, "Stable haptic interaction with virtual environments," IEEE Trans. Robot. Autom., vol. 15, no. 3, pp. 465474, 1999.

[64] B. Hannaford and J.-H. Ryu, "Time-domain passivity control of haptic interfaces," IEEE Trans. Robot. Autom., vol. 18, no. 1, pp. 110, 2002.

[65] J.-H. Ryu, Y. S. Kim, and B. Hannaford, "Sampled- and continuous- time passivity and stability of virtual environments," IEEE Trans. Robot. Autom., vol. 20, no. 4, pp. 772-776, 2004.

[66] J.-H. Ryu, C. Preusche, B. Hannaford, and G. Hirzinger, "Time domain passivity control with reference energy following," IEEE Trans. Control Syst. Technol., vol. 13, no. 5, pp. 737-742, 2005.

[67] S. Stramigioli, C. Secchi, A. J. van der Schaft, and C. Fantuzzi, "Sampled data systems passivity and discrete port-Hamiltonian systems," IEEE Trans. Robot., vol. 21, no. 4, pp. 574-587, 2005.

[68] A. Haddadi and K. Hashtrudi-zaad, "A New Robust Stability Analysis and Design Tool for Bilateral Teleoperation Control Systems," IEEE Int. Conf. Robot. Autom., pp. 663-670, 2008.

[69] B. Willaert, B. Corteville, D. Reynaerts, H. Van Brussel, and E. B. Vander Poorten, "A Mechatronic Analysis of the Classical PositionForce Controller Based on Bounded Environment Passivity," Int. J. Rob. Res., pp. 1-32, 2010.

[70] P. F. Hokayem and M. W. Spong, "Bilateral teleoperation: An historical survey," Automatica, vol. 42, no. 12, pp. 2035-2057, Dec. 2006.

[71] C. Passenberg, A. Peer, and M. Buss, "A survey of environment-, operator-, and task-adapted controllers for teleoperation systems," Mechatronics, vol. 20, no. 7, pp. 787-801, Oct. 2010.

[72] E. Nuño, L. Basañez, and R. Ortega, "Passivity-based control for bilateral teleoperation: A tutorial," Automatica, vol. 47, no. 3, pp. 485-495, Mar. 2011.

[73] P. Puangmali, K. Althoefer, L. D. Seneviratne, D. Murphy, and P. Dasgupta, "State-of-the-art in force and tactile sensing for minimally invasive surgery," IEEE Sens. J., vol. 8, no. 4, pp. 371-380, 2008.

[74] A. Trejos, R. Patel, and M. Naish, "Force sensing and its application in minimally invasive surgery and therapy: a survey," Proc. Inst. Mech. Eng. Part C J. Mech. Eng. Sci., vol. 224, no. 7, pp. 1435-1454, 2010.

[75] T. Watanabe, T. Iwai, Y. Fujihira, L. Wakako, H. Kagawa, and T. Yoneyama, "Force sensor attachable to thin fiberscopes/endoscopes utilizing high elasticity fabric.," Sensors (Basel)., vol. 14, no. 3, pp. 5207-20, Jan. 2014.

[76] M. B. Hong and Y.-H. Jo, "Design and Evaluation of 2-DOF Compliant Forceps With Force-Sensing Capability for Minimally Invasive Robot Surgery," IEEE Trans. Robot., vol. 28, no. 4, pp. 932941, Aug. 2012.

[77] U. Kim, D.-H. Lee, W. J. Yoon, B. Hannaford, and H. R. Choi, "Force Sensor Integrated Surgical Forceps for Minimally Invasive Robotic Surgery," IEEE Trans. Robot., vol. 31, no. 5, pp. 1214-1224, Oct. 2015.

[78] R. Haslinger, P. Leyendecker, and U. Seibold, "A fiberoptic forcetorque-sensor for minimally invasive robotic surgery," in 2013 IEEE International Conference on Robotics and Automation, 2013, pp. 4390-4395.

[79] Z. Kappassov, J.-A. Corrales, and V. Perdereau, "Tactile sensing in dexterous robot hands - Review," Rob. Auton. Syst., vol. 74, pp. 195-220, Dec. 2015.

[80] M. I. Tiwana, S. J. Redmond, and N. H. Lovell, "A review of tactile sensing technologies with applications in biomedical engineering," Sensors Actuators A Phys., vol. 179, pp. 17-31, Jun. 2012.

[81] R. Ahmadi, M. Packirisamy, J. Dargahi, and R. Cecere, "Discretely Loaded Beam-Type Optical Fiber Tactile Sensor for Tissue Manipulation and Palpation in Minimally Invasive Robotic Surgery," IEEE Sens. J., vol. 12, no. 1, pp. 22-32, Jan. 2012.

[82] A. Hassanbeiglou, M. Kalantari, E. Mozaffari, J. Dargahi, and J. Kövecses, "A new tactile array sensor for viscoelastic tissues with time-dependent behavior," Sens. Rev., vol. 35, no. 4, pp. 374-381, Sep. 2015.

[83] B. G. Witmer and M. J. Singer, "Measuring Presence in Virtual Environments: A Presence Questionnaire," Presence Teleoperators virtual Environ., vol. 7, no. 3, pp. 225-240, 1998.

[84] B. Davies, M. Jakopec, S. J. Harris, F. Rodriguez y Baena, A. Barrett, A. Evangelidis, P. Gomes, J. Henckel, and J. Cobb, "Activeconstraint robotics for surgery," Proc. IEEE, vol. 94, no. 9, pp. 16961703, 2006.

[85] J. M. Goldberg and T. Falcone, "Laparoscopic microsurgical tubal anastomosis with and without robotic assistance," Hum. Reprod., vol. 18, no. 1, pp. 145-147, Jan. 2003.

[86] G. Meccariello, F. Faedi, S. AlGhamdi, F. Montevecchi, E. Firinu, C. Zanotti, D. Cavaliere, R. Gunelli, M. Taurchini, A. Amadori, and C. Vicini, "An experimental study about haptic feedback in robotic surgery: may visual feedback substitute tactile feedback?," J. Robot. 
Surg., Nov. 2015.

[87] D. W. Schloerb, "A quantitative measure of telepresence," Presence: Teleoperators and Virtual Environments, vol. 4, no. 1. pp. 64-80, 1995.

[88] S. Jacobs, D. Holzhey, G. Strauss, O. Burgert, and V. Falk, "The impact of haptic learning in telemanipulator-assisted surgery.," Surg. Laparosc. Endosc. Percutan. Tech., vol. 17, no. 5, pp. 402-6, Oct. 2007.

[89] D. Feygin, M. Keehner, and R. Tendick, "Haptic guidance: experimental evaluation of a haptic trainingmethod for a perceptual motor skill," Proc. 10th Symp. Haptic Interfaces Virtual Environ. Teleoperator Syst. HAPTICS 2002, 2002.

[90] "RIO Robotic System." [Online]. Available: http://www.makosurgical.com/physicians/products/rio. [Accessed: 20-Nov-2015].

[91] "ROSA Robotic Device." [Online]. Available: http://medtech.fr/en/rosa1. [Accessed: 20-Nov-2015].

[92] H. Xin, J. S. Zelek, and H. Carnahan, "Laparoscopic surgery, perceptual limitations and force: A review," First Can. Student Conf. Biomed. Comput., pp. 44-46, 2006.

[93] T. Sammour, A. Kahokehr, S. Srinivasa, I. P. Bissett, and A. G. Hill, "Laparoscopic colorectal surgery is associated with a higher intraoperative complication rate than open surgery.," Ann. Surg., vol. 253, no. 1, pp. 35-43, Jan. 2011.

[94] Y. Yang, F. Wang, P. Zhang, C. Shi, Y. Zou, H. Qin, and Y. Ma, "Robot-assisted versus conventional laparoscopic surgery for colorectal disease, focusing on rectal cancer: a meta-analysis.," Ann. Surg. Oncol., vol. 19, no. 12, pp. 3727-36, Nov. 2012.

[95] M. Kroh, K. El-Hayek, S. Rosenblatt, B. Chand, P. Escobar, J. Kaouk, and S. Chalikonda, "First human surgery with a novel singleport robotic system: Cholecystectomy using the da Vinci Single-Site platform," Surg. Endosc. Other Interv. Tech., vol. 25, no. 11, pp. 3566-3573, 2011.

[96] C. Freschi, V. Ferrari, F. Melfi, M. Ferrari, F. Mosca, and a. Cuschieri, "Technical review of the da Vinci surgical telemanipulator," Int. J. Med. Robot. Comput. Assist. Surg., vol. 9, no. 4, pp. 396-406, 2013.

[97] P. Joice, G. B. Hanna, and a Cuschieri, "Errors enacted during endoscopic surgery--a human reliability analysis.," Appl. Ergon., vol. 29, no. 6, pp. 409-414, 1998.

[98] B. Tang, G. B. Hanna, and a. Cuschieri, "Analysis of errors enacted by surgical trainees during skills training courses," Surgery, vol. 138, no. 1, pp. 14-20, 2005.

[99] B. T. Bethea, A. M. Okamura, M. Kitagawa, T. P. Fitton, S. M. Cattaneo, V. L. Gott, W. A. Baumgartner, and D. D. Yuh, "Application of haptic feedback to robotic surgery.," $J$. Laparoendosc. Adv. Surg. Tech. A, vol. 14, no. 3, pp. 191-5, Jun. 2004.

[100] M. Tavakoli, R. V. Patel, and M. Moallem, "Robotic suturing forces in the presence of haptic feedback and sensory substitution," Proc. 2005 IEEE Conf. Control Appl. 2005. CCA 2005., pp. 1-6, 2005.

[101] C. R. Wagner, N. Stylopoulos, and R. D. Howe, "The role of force feedback in surgery: analysis of blunt dissection," Proc. 10th Symp. Haptic Interfaces Virtual Environ. Teleoperator Syst. HAPTICS 2002, 2002.

[102] B. Demi, T. Ortmaier, and U. Seibold, "The touch and feel in minimally invasive surgery," HAVE 2005 IEEE Int. Work. Haptic Audio Vis. Environ. their Appl., vol. 2005, no. October, pp. 33-38, 2005.

[103] T. Ortmaier, B. Deml, B. Kübler, G. Passig, D. Reintsema, and U. Seibold, "Robot assisted force feedback surgery," Springer Tracts Adv. Robot., vol. 31, pp. 361-379, 2007.

[104] S. Schostek, M. O. Schurr, and G. F. Buess, "Review on aspects of artificial tactile feedback in laparoscopic surgery.," Med. Eng. Phys., vol. 31, no. 8, pp. 887-98, Oct. 2009.

[105] J. Rosen, B. Hannaford, M. P. MacFarlane, and M. N. Sinanan, "Force controlled and teleoperated endoscopic grasper for minimally invasive surgery-experimental performance evaluation," IEEE Trans. Biomed. Eng., vol. 46, no. 10, pp. 1212-1221, 1999.

[106] G. Tholey, J. P. Desai, and A. E. Castellanos, "Force feedback plays a significant role in minimally invasive surgery: results and analysis.," Ann. Surg., vol. 241, no. 1, pp. 102-109, 2005.

[107] P. J. Johnson, D. E. Schmidt, and U. Duvvuri, "Output control of da Vinci surgical system's surgical graspers.," J. Surg. Res., vol. 186, no. 1, pp. 56-62, Jan. 2014.
[108] E. P. Westebring-van der Putten, "A Laparoscopic Grasper Handle with Integrated Augmented Tactile Feedback, Designed for Training Grasp Control," in Haptics: Generating and Perceiving Tangible Sensations, Springer Berlin Heidelberg, 2010, pp. 243-250.

[109] C. H. King, M. O. Culjat, M. L. Franco, C. E. Lewis, E. P. Dutson, W. S. Grundfest, and J. W. Bisley, "Tactile feedback induces reduced grasping force in robot-assisted surgery," IEEE Trans. Haptics, vol. 2, no. 2, pp. 103-110, 2009.

[110] C. R. Wottawa, B. Genovese, B. N. Nowroozi, S. D. Hart, J. W. Bisley, W. S. Grundfest, and E. P. Dutson, "Evaluating tactile feedback in robotic surgery for potential clinical application using an animal model.," Surg. Endosc., Oct. 2015.

[111] W. McMahan, J. Gewirtz, D. Standish, P. Martin, J. a. Kunkel, M. Lilavois, A. Wedmid, D. I. Lee, and K. J. Kuchenbecker, "Tool contact acceleration feedback for telerobotic surgery," IEEE Trans. Haptics, vol. 4, no. 3, pp. 210-220, 2011.

[112] K. Bark, W. McMahan, A. Remington, J. Gewirtz, A. Wedmid, D. I. Lee, and K. J. Kuchenbecker, "In vivo validation of a system for haptic feedback of tool vibrations in robotic surgery.," Surg. Endosc., vol. 27, no. 2, pp. 656-64, Feb. 2013.

[113] J. K. Koehn and K. J. Kuchenbecker, "Surgeons and non-surgeons prefer haptic feedback of instrument vibrations during robotic surgery," Surg. Endosc., pp. 1-14, 2015.

[114] D. A. a Lawrence, "Impedance control stability properties in common implementations," IEEE Int. Conf. Robot. Autom., pp. 1185-1190, 1988.

[115] J. Roy, D. L. Rothbaum, and L. L. Whitcomb, "Haptic feedback augmentation through position based adaptive force scaling: theory and experiment," in IEEE/RSJ International Conference on Intelligent Robots and System, 2002, vol. 3, pp. 2911-2919.

[116] E. Beretta, F. Nessi, G. Ferrigno, F. Di Meco, A. Perin, L. Bello, G. Casaceli, F. Raneri, A. De Benedictis, and E. De Momi, "Enhanced torque-based impedance control to assist brain targeting during openskull neurosurgery: A feasibility study," Int. J. Med. Robot. Comput. Assist. Surg., p. n/a-n/a, 2015.

[117] N. Abolhassani, R. Patel, and M. Moallem, "Needle insertion into soft tissue: A survey," Med. Eng. Phys., vol. 29, no. 4, pp. 413-431, 2007.

[118] O. Gerovichev, P. Marayong, and A. M. Okamura, "The Effect of Visual and Haptic Feedback on Manual and Teleoperated Needle Insertion," MICCAI '02 Proc. 5th Int. Conf. Med. Image Comput. Comput. Interv. I, pp. 147-154, 2002.

[119] D. De Lorenzo, E. De Momi, I. Dyagilev, R. Manganelli, A. Formaglio, D. Prattichizzo, M. Shoham, and G. Ferrigno, "Force feedback in a piezoelectric linear actuator for neurosurgery.," Int. J. Med. Robot., vol. 7, no. 3, pp. 268-75, Sep. 2011.

[120] A. M. Okamura, C. Simone, and M. D. O'Leary, "Force modeling for needle insertion into soft tissue.," IEEE Trans. Biomed. Eng., vol. 51, no. 10, pp. 1707-16, Oct. 2004.

[121] L. Barbe, B. Bayle, M. de Mathelin, and A. Gangi, "In Vivo Model Estimation and Haptic Characterization of Needle Insertions," Int. J. Rob. Res., vol. 26, no. 11-12, pp. 1283-1301, Nov. 2007.

[122] H. Kataoka, T. Washio, K. Chinzei, K. Mizuhara, C. Simone, and A. M. Okamura, Measurement of the Tip and Friction Force Acting on a Needle during Penetration, vol. 2488. Berlin, Heidelberg: Springer Berlin Heidelberg, 2002.

[123] D. De Lorenzo, Y. Koseki, E. De Momi, K. Chinzei, and A. M. Okamura, "Coaxial needle insertion assistant with enhanced force feedback," IEEE Trans. Biomed. Eng., vol. 60, no. 2, pp. 379-389, Feb. 2013.

[124] J. Konstantinova, A. Jiang, K. Althoefer, P. Dasgupta, and T. Nanayakkara, "Implementation of tactile sensing for palpation in robot-assisted minimally invasive surgery: A review," IEEE Sens. J., vol. 14 , no. 8, pp. 2490-2501, 2014.

[125] M. Li, S. Luo, T. Nanayakkara, L. D. Seneviratne, P. Dasgupta, and K. Althoefer, "Multi-fingered haptic palpation using pneumatic feedback actuators," Sensors Actuators A Phys., vol. 218, pp. 132141, Oct. 2014.

[126] S. McKinley, A. Garg, S. Sen, R. Kapadia, A. Murali, K. Nichols, S. Lim, S. Patil, P. Abbeel, A. M. Okamura, and K. Goldberg, "A singleuse haptic palpation probe for locating subcutaneous blood vessels in robot-assisted minimally invasive surgery," in 2015 IEEE International Conference on Automation Science and Engineering (CASE), 2015, pp. 1151-1158.

[127] A. P. Åstrand, B. M. Andersson, V. Jalkanen, and O. A. Lindahl, "Initial Measurements on Whole Human Prostate ex vivo with a 
Tactile Resonance Sensor in Order to Detect Prostate Cancer," 16th Nordic-Baltic Conference on Biomedical Engineering October 1416, 2014, Gothenburg, Sweden. pp. 120-123, 2015.

[128] C. Pacchierotti, D. Prattichizzo, and K. J. Kuchenbecker, "Cutaneous Feedback of Fingertip Deformation and Vibration for Palpation in Robotic Surgery," IEEE Trans. Biomed. Eng., vol. 63, no. 2, pp. 278287, Feb. 2016.

[129] H. Liu, J. Li, X. Song, L. D. Seneviratne, and K. Althoefer, "Rolling Indentation Probe for Tissue Abnormality Identification During Minimally Invasive Surgery," IEEE Trans. Robot., vol. 27, no. 3, pp. 450-460, Jun. 2011.

[130] M. Li, A. Faragasso, J. Konstantinova, V. Aminzadeh, L. D. Seneviratne, P. Dasgupta, and K. Althoefer, "A novel tumor localization method using haptic palpation based on soft tissue probing data," in 2014 IEEE International Conference on Robotics and Automation (ICRA), 2014, pp. 4188-4193.

[131] D.-S. Kwon, K. Y. Woo, S. K. Song, W. S. Kim, and H. S. Cho, "Microsurgical telerobot system," in Proceedings. 1998 IEEE/RSJ International Conference on Intelligent Robots and Systems. Innovations in Theory, Practice and Applications (Cat. No.98CH36190), vol. 2, pp. 945-950.

[132] S. Charles, H. Das, T. Ohm, C. Boswell, G. Rodriguez, R. Steele, and D. Istrate, "Dexterity-enhanced telerobotic microsurgery," in 1997 8th International Conference on Advanced Robotics. Proceedings. ICAR'97, 1997, pp. 5-10.

[133] K. Hongo, S. Kobayashi, Y. Kakizawa, J.-I. Koyama, T. Goto, H. Okudera, K. Kan, M. G. Fujie, H. Iseki, and K. Takakura, "NeuRobot: telecontrolled micromanipulator system for minimally invasive microneurosurgery-preliminary results.," Neurosurgery, vol. 51, no. 4, pp. 985-8; discussion 988, Oct. 2002.

[134] R. Taylor, "A Steady-Hand Robotic System for Microsurgical Augmentation," Int. J. Rob. Res., vol. 18, no. 12, pp. 1201-1210, Dec. 1999.

[135] J. D. Pitcher, J. T. W. Wilson, S. D. Schwartz, J. P. Hubschman, and T. C. Tsao, "Robotic Eye Surgery: Past, Present, and Future," $J$. Comput. Sci. Syst. Biol., vol. 3, pp. 1-4, 2012.

[136] P. J. Berkelman, L. L. Whitcomb, R. H. Taylor, and P. Jensen, A Miniature Microsurgical Instrument Tip Force Sensor for Enhanced Force Feedback During Robot-Assisted Manipulation, vol. 19, no. 5. Springer Berlin Heidelberg, 2003.

[137] R. Kumar, P. Berkelman, P. Gupta, A. Barnes, P. S. Jensen, L. L. Whitcomb, and R. H. Taylor, "Preliminary experiments in cooperative human/robot force control for robot assisted microsurgical manipulation," in Proceedings 2000 ICRA. Millennium Conference. IEEE International Conference on Robotics and Automation. Symposia Proceedings (Cat. No.00CH37065), 2000, vol. 1, pp. 610-617.

[138] M. Balicki, A. Uneri, I. Iordachita, J. Handa, P. Gehlbach, and R. Taylor, "Micro-force sensing in robot assisted membrane peeling for vitreoretinal surgery," in International Conference on Medical Image Computing and Computer Assisted Intervention, 2010, vol. 13, pp. 303-310.

[139] X. He, M. Balicki, P. Gehlbach, J. Handa, R. Taylor, and I. Iordachita, "A multi-function force sensing instrument for variable admittance robot control in retinal microsurgery," in 2014 IEEE International Conference on Robotics and Automation (ICRA), 2014, vol. 13, pp. 1411-1418.

[140] T. S. Wells, S. Yang, R. A. MacLachlan, L. A. Lobes, J. N. Martel, and C. N. Riviere, "Hybrid position/force control of an active handheld micromanipulator for membrane peeling.," Int. J. Med. Robot., May 2015.

[141] S. Yang, R. A. MacLachlan, and C. N. Riviere, "Manipulator Design and Operation for a Six-Degree-of-Freedom Handheld TremorCanceling Microsurgical Instrument.," IEEE ASME Trans. Mechatron., vol. 20, no. 2, pp. 761-772, Apr. 2015.

[142] B. M. Wolfe, Z. Szabo, M. E. Moran, P. Chan, and J. G. Hunter, "Training for minimally invasive surgery," Surg. Endosc., vol. 7, no. 2, pp. 93-95, 1993.

[143] G. M. Fried, L. S. Feldman, M. C. Vassiliou, S. A. Fraser, D. Stanbridge, G. Ghitulescu, and C. G. Andrew, "Proving the value of simulation in laparoscopic surgery.," Ann. Surg., vol. 240, no. 3, pp. 518-25; discussion 525-8, Sep. 2004.

[144] G. M. Fried, A. M. Derossis, J. Bothwell, and H. H. Sigman, "Comparison of laparoscopic performance in vivo with performance measured in a laparoscopic simulator," Surg. Endosc., vol. 13, no. 11, pp. 1077-1081, Apr. 1999.

[145] R. M. Satava, "Virtual reality surgical simulator," Surg. Endosc., vol. 7, no. 3, pp. 203-205, 1993.

[146] L. Moody and T. N. Arvanitis, "Objective Metrics for the Evaluation of Simple Surgical," pp. 207-221, 2000.

[147] N. E. Seymour, A. G. Gallagher, S. A. Roman, M. K. O'Brien, V. K. Bansal, D. K. Andersen, and R. M. Satava, "Virtual reality training improves operating room performance: results of a randomized, double-blinded study.," Ann. Surg., vol. 236, no. 4, pp. 458-63; discussion 463-4, Oct. 2002.

[148] F. H. Halvorsen, O. J. Elle, V. V Dalinin, B. E. Mørk, V. Sørhus, J. S. Røtnes, and E. Fosse, "Virtual reality simulator training equals mechanical robotic training in improving robot-assisted basic suturing skills.," Surg. Endosc., vol. 20, no. 10, pp. 1565-9, Oct. 2006.

[149] J. M. Albani and D. I. Lee, "Virtual reality-assisted robotic surgery simulation.," J. Endourol., vol. 21, no. 3, pp. 285-7, Mar. 2007.

[150] J. D. Hernandez, S. D. Bann, Y. Munz, K. Moorthy, V. Datta, S. Martin, A. Dosis, F. Bello, A. Darzi, and T. Rockall, "Qualitative and quantitative analysis of the learning curve of a simulated surgical task on the da Vinci system.," Surg. Endosc., vol. 18, no. 3, pp. 372-8, Mar. 2004.

[151] S. Rehman, S. J. Raza, A. P. Stegemann, K. Zeeck, R. Din, A. Llewellyn, L. Dio, M. Trznadel, Y. W. Seo, A. J. Chowriappa, T. Kesavadas, K. Ahmed, and K. A. Guru, "Simulation-based robotassisted surgical training: a health economic evaluation.," Int. J. Surg., vol. 11, no. 9, pp. 841-6, Jan. 2013.

[152] E. A. M. Heijnsdijk, A. Pasdeloup, A. J. van der Pijl, J. Dankelman, and D. J. Gouma, "The influence of force feedback and visual feedback in grasping tissue laparoscopically.," Surg. Endosc., vol. 18, no. 6, pp. 980-5, Jun. 2004.

[153] P. Lamata, E. J. Gómez, F. M. Sánchez-Margallo, F. Lamata, F. del Pozo, and J. Usón, "Tissue consistency perception in laparoscopy to define the level of fidelity in virtual reality simulation.," Surg. Endosc., vol. 20, no. 9, pp. 1368-75, Sep. 2006.

[154] P. A. Kenney, M. F. Wszolek, J. J. Gould, J. A. Libertino, and A. Moinzadeh, "Face, content, and construct validity of dV-trainer, a novel virtual reality simulator for robotic surgery.," Urology, vol. 73, no. 6, pp. 1288-92, Jun. 2009.

[155] M. A. Lerner, M. Ayalew, W. J. Peine, and C. P. Sundaram, "Does Training on a Virtual Reality Robotic Simulator Improve Performance on the da Vinci ® Surgical System?," J. Endourol., vol. 24, no. 3, pp. 467-472, Mar. 2010.

[156] I. Brouwer, J. Ustin, L. Bentley, A. Sherman, N. Dhruv, and F. Tendick, "Measuring in vivo animal soft tissue properties for haptic modeling in surgical simulation," Stud. Health Technol. Inform., vol. 81, pp. 69-74, 2001.

[157] M. Agus, A. Giachetti, E. Gobbetti, G. Zanetti, A. Zorcolo, B. Picasso, and S. S. Franceschini, "A haptic model of a bone-cutting burr,” Stud. Health Technol. Inform., vol. 94, pp. 4-10, 2003.

[158] R. Alterovitz, J. Pouliot, R. Taschereau, I. C. Joe Hsu, and K. Goldberg, "Simulating needle insertion and radioactive seed implantation for prostate brachytherapy," Stud. Health Technol. Inform., vol. 94, pp. 19-25, 2003.

[159] P. Gorman, T. Krummel, R. Webster, M. Smith, and D. Hutchens, "A prototype haptic lumbar puncture simulator," Stud. Health Technol. Inform., vol. 70, pp. 106-109, 2000.

[160] V. Vuskovic, M. Kauer, G. Szekely, and M. Reidy, "Realistic force feedback for virtual reality based diagnostic surgery simulators," in Proceedings 2000 ICRA. IEEE International Conference on Robotics and Automation, 2000, vol. 2, pp. 1592-1598.

[161] T. R. Coles, D. Meglan, and N. W. John, "The role of haptics in medical training simulators: A survey of the state of the art," IEEE Trans. Haptics, vol. 4, no. 1, pp. 51-66, 2011.

[162] K. A. Kaczmarek, J. G. Webster, P. Bach-y-Rita, and W. J. Tompkins, "Electrotactile and vibrotactile displays for sensory substitution systems.," IEEE Trans. Biomed. Eng., vol. 38, no. 1, pp. 1-16, Jan. 1991.

[163] V. Hayward, "A brief taxonomy of tactile illusions and demonstrations that can be done in a hardware store.," Brain Res. Bull., vol. 75, no. 6, pp. 742-52, Apr. 2008.

[164] D. Prattichizzo, C. Pacchierotti, S. Cenci, K. Minamizawa, and G. Rosati, "Using a fingertip tactile device to substitute kinesthetic feedback in haptic interaction," Lect. Notes Comput. Sci. (including Subser. Lect. Notes Artif. Intell. Lect. Notes Bioinformatics), vol. 
6191 LNCS, no. PART 1, pp. 125-130, 2010.

[165] L. Meli, C. Pacchierotti, and D. Prattichizzo, "Sensory Subtraction in Robot-Assisted Surgery: Fingertip Skin Deformation Feedback to Ensure Safety and Improve Transparency in Bimanual Haptic Interaction," IEEE Trans. Biomed. Eng., vol. 61, no. 4, pp. 13181327, Apr. 2014.

[166] M. Kitagawa, D. Dokko, A. M. Okamura, and D. D. Yuh, "Effect of sensory substitution on suture-manipulation forces for robotic surgical systems.," J. Thorac. Cardiovasc. Surg., vol. 129, no. 1, pp. 151-8, Jan. 2005.

[167] T. Akinbiyi, C. E. Reiley, S. Saha, D. Burschka, C. J. Hasser, D. D. Yuh, and A. M. Okamura, "Dynamic augmented reality for sensory substitution in robot-assisted surgical systems.," Conf. Proc. ... Annu. Int. Conf. IEEE Eng. Med. Biol. Soc. IEEE Eng. Med. Biol. Soc. Annu. Conf., vol. 1, pp. 567-70, Jan. 2006.

[168] M. Tavakoli, a. Aziminejad, R. V. Patel, and M. Moallem, "Methods and mechanisms for contact feedback in a robot-assisted minimally invasive environment," Surg. Endosc. Other Interv. Tech., vol. 20, no. 10 , pp. $1570-1579,2006$.

[169] C. D. Wickens, "Multiple Resources and Mental Workload," Hum. Factors J. Hum. Factors Ergon. Soc., vol. 50, no. 3, pp. 449-455, Jun. 2008.

[170] S. Shoval, M. Wagner, and E. Porat, "Reconstructing haptic sensing in tele-robotics surgery by non-attentive visual method," 2011 IEEE Int. Conf. Robot. Biomimetics, ROBIO 2011, pp. 437-442, 2011.

[171] L. B. Rosenberg, "The Use of Virtual Fixtures as Perceptual Overlays to Enhance Operator Performance in Remote Environments.," Interim report, Stanford Univ. CA Cent. Des. Res., Sep. 1992.

[172] B. L. Davies, S. J. Harris, W. J. Lin, R. D. Hibberd, R. Middleton, and J. C. Cobb, "Active compliance in robotic surgery--the use of force control as a dynamic constraint," Proc. Inst. Mech. Eng. Part H J. Eng. Med., vol. 211, no. 4, pp. 285-292, Apr. 1997.

[173] J. J. Abbott and a. M. Okamura, "Virtual fixture architectures for telemanipulation," 2003 IEEE Int. Conf. Robot. Autom. (Cat. No.03CH37422), pp. 2798-2805, 2003.

[174] A. Bettini, P. Marayong, S. Lang, A. M. Okamura, and G. D. Hager, "Vision-assisted control for manipulation using virtual fixtures," IEEE Trans. Robot., vol. 20, no. 6, pp. 953-966, 2004.

[175] T. Yamamoto, N. Abolhassani, S. Jung, A. M. Okamura, and T. N. Judkins, "Augmented reality and haptic interfaces for robot-assisted surgery," Int. J. Med. Robot. Comput. Assist. Surg., vol. 8, no. November 2011, pp. 45-56, 2012.

[176] M. Citak, E. M. Suero, M. Citak, N. J. Dunbar, S. H. Branch, M. A. Conditt, S. A. Banks, and A. D. Pearle, "Unicompartmental knee arthroplasty: is robotic technology more accurate than conventional technique?," Knee, vol. 20, no. 4, pp. 268-71, Aug. 2013.

[177] A. Mofidi, J. F. Plate, B. Lu, M. A. Conditt, J. E. Lang, G. G. Poehling, and R. H. Jinnah, "Assessment of accuracy of robotically assisted unicompartmental arthroplasty.," Knee Surg. Sports Traumatol. Arthrosc., vol. 22, no. 8, pp. 1918-25, Aug. 2014.

[178] "Alf-X." [Online]. Available: http://www.alf-x.com/en/. [Accessed: 20-Nov-2015].

[179] "Titan Medical Product." [Online]. Available: http://www.titanmedicalinc.com/product/. [Accessed: 20-Nov2015].

[180] "ACTIVE - Active Constraints Technologies for Ill-defined or Volatile Environments." [Online]. Available: www.active-fp7.eu. [Accessed: 19-Aug-2015].

[181] "M7 Surgical Robot." [Online]. Available: www.sri.com/engage/products-solutions/m7-surgical-robot. [Accessed: 20-Nov-2015].

[182] "MiroSurge - Telemanipulation in Minimally Invasive Surgery." [Online].

http://www.dlr.de/rmc/rm/en/desktopdefault.aspx/tabid-

3795/16616_read-40529/. [Accessed: 20-Nov-2015].

[183] "Sofie." [Online]. Available: https://www.tue.nl/en/research/research-institutes/roboticsresearch/projects/sofie/. [Accessed: 20-Nov-2015].

[184] H. Shennib, A. Bastawisy, M. J. Mack, and F. H. Moll, "Computerassisted telemanipulation: an enabling technology for endoscopic coronary artery bypass.," Ann. Thorac. Surg., vol. 66, no. 3, pp. 1060-3, Sep. 1998.

[185] C. P. Delaney, a C. Lynch, A. J. Senagore, and V. W. Fazio, "Comparison of robotically performed and traditional laparoscopic colorectal surgery.," Dis. Colon Rectum, vol. 46, no. 12, pp. 1633-
1639, 2003.

[186] M. Morino, L. Pellegrino, C. Giaccone, C. Garrone, and F. Rebecchi, "Randomized clinical trial of robot-assisted versus laparoscopic Nissen fundoplication.," Br. J. Surg., vol. 93, no. 5, pp. 553-8, May 2006.

[187] C. N. Gutt, T. Oniu, A. Mehrabi, A. Kashfi, P. Schemmer, and M. W. Büchler, "Robot-assisted abdominal surgery.," Br. J. Surg., vol. 91, no. 11, pp. 1390-7, Nov. 2004.

[188] I. El Nakadi, C. Mélot, J. Closset, V. Demoor, K. Bétroune, P. Feron, P. Lingier, and M. Gelin, "Evaluation of da Vinci Nissen fundoplication clinical results and cost minimization," World $J$. Surg., vol. 30, no. 6, pp. 1050-1054, 2006.

[189] G. A. Antoniou, C. V Riga, E. K. Mayer, N. J. W. Cheshire, and C. D. Bicknell, "Clinical applications of robotic technology in vascular and endovascular surgery.," J. Vasc. Surg., vol. 53, no. 2, pp. 493-9, Feb. 2011.

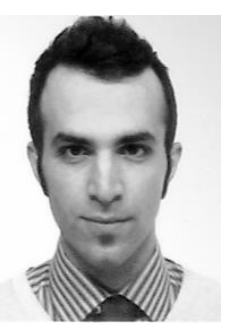

Nima Enayati received the B.Sc. degree in mechanical engineering K. N. T. University of Technology, Tehran, Iran, in 2011 and the M.Sc. degree in Automation from Politecnico di Milano, Italy, in 2013. He is currently working towards the Ph.D. degree in Neuroengineering and Medical Robotics Laboratory (NearLab) at Politecnico di Milano, Italy. His current research interests include surgical robotics, teleoperation and haptics.

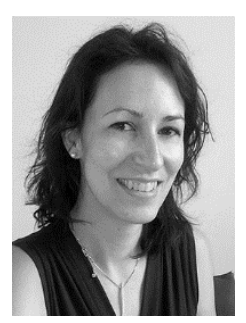

Elena De Momi received the M.Sc. and $\mathrm{Ph} . \mathrm{D}$. degrees in biomedical engineering from the Politecnico di Milano, Milan, Italy, in 2002 and 2006, respectively. She is an Assistant Professor at the Department of Electronics, Information and Bioengineering, Politecnico di Milano. She is the Principal Investigator of the EDEN2020 EU project for the Politecnico di Milano. Dr. De Momi has participated at several national and European grants in the field of computer assisted surgery, keyhole robotic neurosurgery, and awake robotic neurosurgery. She collaborates as an expert with the European Commission in the 7th Framework Program. Her current research interests include computer-aided surgery, medical robotics, biomechanics, and sensors. She is part of the Editorial Board of IJARS and JMRR.

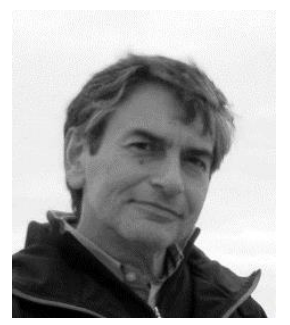

Giancarlo Ferrigno, M.Sc. in electrical engineering and $\mathrm{Ph} . \mathrm{D}$. in Bioengineering. Founder of the Neuroengineering and Medical Robotics Laboratory in 2008, is Full Professor of Medical Robotics at the Computer science, Electronics and Bioengineering department (DEIB) of Politecnico di Milano where he is Chair of the Biomedical Division. He has been the European Coordinator of three FP7-EU projects in ICT: ROBOCAST (2008-2010) and ACTIVE (2011-2015) were in the field of the Surgical Robotics. MUNDUS (2010-2013) in the field of Assistive and Rehabilitative Robotics. He has co-authored about 200 papers. He is working in the ISO standard group for Surgical Robots and organized several workshops in the surgical robotics. 